\title{
Design and investigation of a high-sensitivity PCF sensor for the detection of sulfur dioxide
}

\section{Mohamed Nizar ( $\nabla$ nizar.shabu@gmail.com )}

IFET College of Engineering https://orcid.org/0000-0003-4254-7744

\section{Elizabeth Caroline}

IFET College of Engineering

\section{Prabu Krishnan}

NITK Surathkal: National Institute of Technology Karnataka

\section{Research Article}

Keywords: Photonic crystal fiber, Finite Element Method, Perfectly Matched Layer, Relative sensitivity

Posted Date: March 10th, 2021

DOI: https://doi.org/10.21203/rs.3.rs-300395/v1

License: (1) This work is licensed under a Creative Commons Attribution 4.0 International License. Read Full License 


\title{
Design and investigation of a high-sensitivity PCF sensor for the detection of sulfur dioxide
}

\author{
Mohamed Nizar ${ }^{*}$, Elizabeth Caroline ${ }^{2}$, Prabu Krishnan ${ }^{3}$ \\ ${ }^{1}$ Department of Electronics and Communication Engineering, IFET College of Engineering, India, Email: \\ nizar.shabu@gmail.com , Tel: *(91) 7094647170 (M.N); \\ ${ }^{2}$ Department of Electronics and Communication Engineering, IFET College of Engineering, Villupuram, \\ Tamilnadu, India, Email: carolinebritto96@gmail.com ，Tel: *(91) 9489462260 (E.C); \\ ${ }^{3}$ Department of Electronics and Communication Engineering, National Institute of Technology Karnataka, \\ Surathkal, India \\ Email: prabuk@ nitk.edu.in, Tel: *(91) 9884888408 (P.K); \\ *Corresponding Author
}

\begin{abstract}
A vertical photonic crystal fiber (V-PCF) and horizontal PCF (H-PCF) are designed for the detection of sulfur dioxide $\left(\mathrm{SO}_{2}\right)$ in this paper. A demanding numerical investigation is carried out in a wider range of wavelengths from $0.8 \mu \mathrm{m}$ to $1 \mu \mathrm{m}$. $\mathrm{SO}_{2}$ is a major contributor to air pollution, which is responsible for asthma and cancer. The optical parameters are analyzed by using the Finite Element Method (FEM) which consumes a completely circular isotropic Perfectly Matched Layer (PML). The designed V-PCF sensor test is performed with different PML radius values, different elliptical constants for the inner cladding, the outer cladding layer, and the core. The higher relative sensitivity of 59.34\% makes this proposed V-PCF a good design for $\mathrm{SO}_{2}$ detection.
\end{abstract}

Keywords: Photonic crystal fiber, Finite Element Method, Perfectly Matched Layer, Relative sensitivity

\section{Introduction}

Sulfur dioxide $\left(\mathrm{SO}_{2}\right)$ is an incomprehensible gas, with a pungent smell. Approximately $99 \%$ of airborne $\mathrm{SO}_{2}$ originates from human resources. In the United States, where the population is larger, a study was carried out on 20,472 children and adults. Respiratory diseases are found to be diagnosed because of $\mathrm{SO}_{2}$. Areas that have produced this $\mathrm{SO}_{2}$, such as the Salt Lake Basin and Rocky Mountain, cause lower respiratory disease in children [1]. Photonic crystal fiber (PCF) is a fast-growing field that, since the last eras, has attracted incredible attention. By attaching and limiting air holes at regular intervals, the PCF guides the light, and these holes run along the length of the fibers. By varying the size of holes in the core and cladding, the propagation 
of light can be regulated. Because of its ability to control light in hollow bodies, the loss of blockage is very low and the contact of light is increased, resulting in increased fiber sensitivity [2]. A number of reported works [3-16] have been developed to investigate the performance of optical sensors based on PCF. In several applications, PCF is used, such as gas detection [3-4], chemical detection [5-6], pressure detection [7], biomedical and temperature sensing, etc. Conventional fibers suffer from limited design flexibility in the core and increased complexity in finding lower value containment loss and sensitivity, limited core size, and difficult selection of materials [8-9]. For gas sensors and liquid sensors, the hollow-core PCFs are more suited. Hollow-core fiber is an optical fiber that guides light in the hollow region [10-11]. As a result, only a minimum amount of light will spread to the solid fiber material (typically a glass). These fibers are called photonic band gap fibers. The unique feature of the hollow core is that it will allow the control of the gas compositions and provide long interactions between the light and the gas. Hollow-core fiber reduces nonlinearity as only a small amount of light propagates in silica; the effect of non-linearity will be greatly reduced compared to concrete core fibers. These bio-sensing and chemical senses play an important role in medical science. As a result, most researchers keep an eye on the detection of fluid, chemical, and gas sensitivities [12-16]. Several numbers of research studies on gas detection were reported. Micro-structured [17] $\mathrm{GeO}_{2}$ doped silica PCF achieved a relative sensitivity of $16.88 \%$. The hybrid PCF gas sensor generates $15.67 \%$ relative sensitivity to $1.33 \mu \mathrm{m}$ wavelength.

The index guiding [19] PCF was projected for gas detection applications and achieved a relative sensitivity of $32.99 \%$. Hexagonal, porous PCF sensor produced a relative sensitivity of $42.27 \%$ for a wavelength of $1.3 \mu \mathrm{m}$ [20], followed by $53.07 \%$ for a PCF-based gas sensor [21]. Sensitivity of $55.10 \%$ to the $1.33 \mu \mathrm{m}$ wavelength for spiral PCF [22] was also achieved. In the Porous Core PCF sensor [23], the gas was detected in the terahertz region and a propagation loss of $0.013 \mathrm{~dB} / \mathrm{m}$ was achieved. This sensor detects toxic gases, with a sensitivity of $0.268 \% / \mathrm{ppm}$. Highly sensitive hydrogen sulfide $\left(\mathrm{H}_{2} \mathrm{~S}\right)$ gas sensor using a combination of graphene properties was proposed. The relative sensitivity of $1.2 \times 104 \mathrm{~nm} / \mathrm{RIU}$ for $\mathrm{H}_{2} \mathrm{~S}$ gas 
[24] was achieved with this method. $\mathrm{H}_{2} \mathrm{~S}$ gas was detected by the PCF Mach-Zehnder interferometer [25]. Titanium dioxide/amino-functionalized graphene quantum dots are coated over the PCF surface to detect $\mathrm{H}_{2} \mathrm{~S}$. The relative sensitivity of $26.62 \mathrm{ppm}-1$ was achieved using this method.

The V-PCF structure with different elliptical core and cladding is investigated in this proposed work. Elliptical air holes in the cladding with an additional elliptical constant are considered to be high sensitivity and low confinement loss. In order to understand the properties of elliptical air holes, configurations of vertical and horizontal air holes are analyzed. The relative sensitivity and confinement loss of the proposed V-PCF structures against accurate gas analysts are examined and precisely compared. In addition, the sensitivity of the proposed gas sensor is compared to other PCF sensors.

\section{Design Methodology}

The outer and inner elliptical sheaths are designed vertically and horizontally in PCF structures, and then the elliptical core is shaped, as shown in Figures 1a and 1b. In the cladding and core region, the elliptic holes are constructed to achieve high relative sensitivity and low confinement loss at the same time. COMSOL Multiphysics software examines the features of the V-PCF and H-PCF with FEM.

\subsection{V-PCF Sensor design}

Figure 1a illustrates the proposed V-PCF gas sensor. The V-PCF consists of two outer cladding layers and one inner cladding layer, and the core surrounds the center circle. The outer cladding, inner cladding, and core are elliptical. The elliptical shape of these different layers is denoted by an elliptical constant $\eta$ and is

represented as $=\frac{d_{b}}{d_{a}}$, where $d_{a}$ and $d_{b}$ are the a-semi-axis and b-semi-axis, respectively [6]. The number of air holes in the outer cladding layers is 24 and 18, respectively. The third inner cladding layer has 16 air holes. The elliptical constant of third cladding layer is 0.625 [a-semi-axis $=0.8 \mu \mathrm{m}$ and b-semi-axis $=0.5 \mu \mathrm{m}]$. The size of the elliptical core is 0.71 [a-semi-axis $=0.7 \mu \mathrm{m}$ and $\mathrm{b}$-semi-axis $=0.5 \mu \mathrm{m}$ ]. The center air hole is circular and a refractive index (RI) of 1 . The lattice pitch period amid two neighboring holes of the proposed gas sensor is symbolized as $\Lambda$ and is about $1.8 \mu \mathrm{m}$. This design aims to confine the light in the core area. An active 
boundary setting is done by adding the PML at the geometry's outer area, which is required to avoid scattering loss.

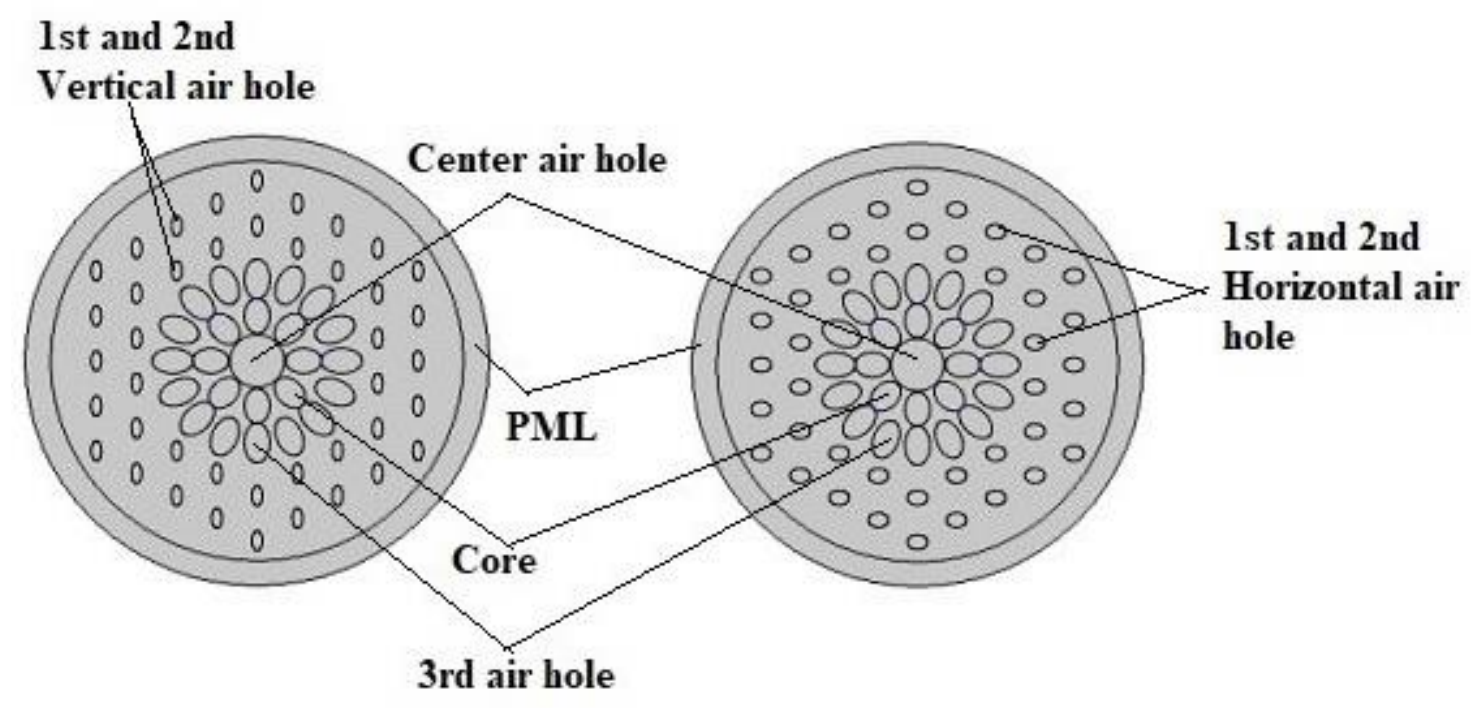

1(a) Structure of V-PCF sensor

1(b) Structure of H-PCF sensor

Fig. 1. PCF gas sensor diagram

\subsection{H-PCF sensor design}

The elliptical outer cladding air holes are placed horizontally on the H-PCF sensor design, as shown in figure $1 \mathrm{~b}$. The structure consists of three elliptical cladding layers and one elliptical core layer. The two exterior cladding layers with a horizontal elliptic air hole have an elliptical constant of 1.33 . The elliptical constant of the third cladding layer and the core are 0.625 and 0.714 , respectively. If the pitch value is increased or decreased in this structure, the result is significantly less, and the pitch value of this H-PCF is $1.8 \mu \mathrm{m}$. Three different PML values are analyzed, and the best the best one is compared to the best vertical PML. The outer two elliptical constants of V-PCF and H-PCF are compared with the different elliptical constant values shown in Figures $2 \mathrm{a}$ and $2 \mathrm{~b}$. It is inferred from the figures that the V-PCF and H-PCF sensors produce a high sensitivity of 0.75 and 1.33 elliptical constants. Considering the best elliptical constant outer cladding for the V-PCF and H-PCF sensors, different elliptical constants for inner cladding and core are 
analyzed. Figures $2 \mathrm{c}$ and $2 \mathrm{~d}$ show that the elliptical constant of 0.625 and 0.71 for internal cladding and core produces the best sensitivity. The structure of the gas sensors is designed to detect $\mathrm{SO}_{2}$.
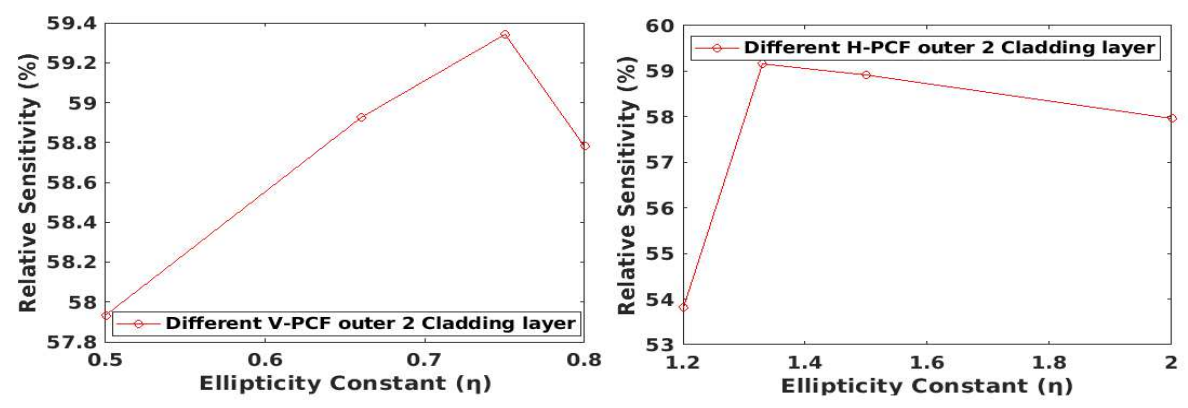

2(a) V-PCF outer cladding

2(b) H-PCF outer cladding
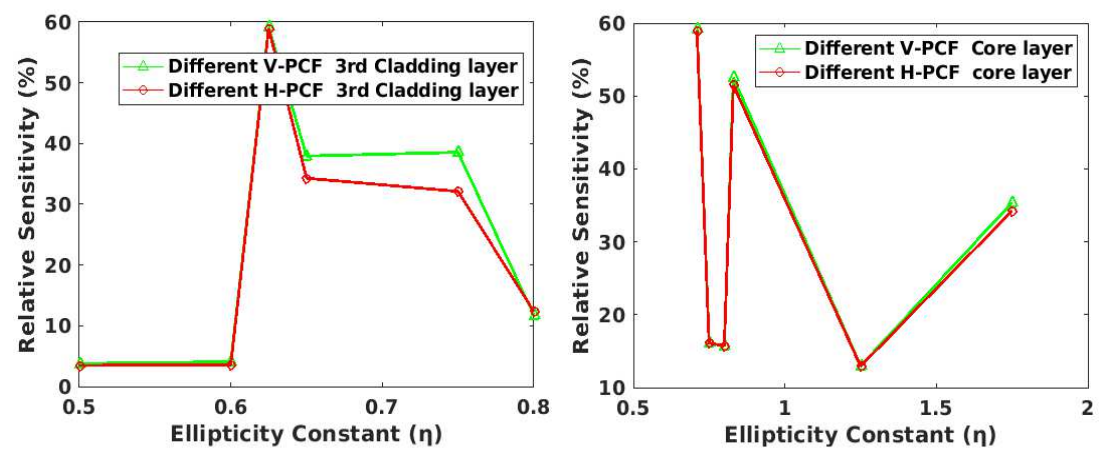

2(c) Comparison graph for inner cladding 2(d) Comparison graph for the core layer

Fig. 2. Comparison graph for different elliptical constant

To analyze the proposed gas sensor's performance with a wavelength of $0.8 \mu \mathrm{m}$ to $1 \mu \mathrm{m}$, the parameters such as relative sensitivity, effective area, attenuation, and confinement loss are very significant. The relative sensitivity can be expressed as follows,

$$
\begin{aligned}
& r \alpha n_{r} \\
& r=\frac{n_{r}}{n_{\text {eff }}} \times f
\end{aligned}
$$

where $n_{r}$ the RI of the material to be sensed, $n_{e f f}$ is the effective RI of the model, and $f$ is the power ratio in percent. The power ratio is defined in the equation, (3)

$$
f=\frac{\int_{\text {Sample }} \operatorname{Re}\left(E_{x} H_{y}-E_{y} H_{x}\right) d x d y}{\int_{\text {total }} \operatorname{Re}\left(E_{x} H_{y}-E_{y} H_{x}\right) d x d y} \times 100
$$


$\mathrm{H}_{\mathrm{y}}, \mathrm{H}_{\mathrm{x}}$, and $\mathrm{E}_{\mathrm{y}}, \mathrm{E}_{\mathrm{x}}$ are transverse magnetic and electric fields in the $\mathrm{y}$ and $\mathrm{x}$-axis, respectively. The confinement loss is calculated using the imaginary part of the good RI values shown in Equation (4).

$$
\begin{aligned}
& L_{c}=8.686 k_{0} x I_{m}\left(n_{\text {eff }}\right) \times 10^{6} \\
& \mathrm{k}_{0}=\frac{2 \pi}{\lambda}
\end{aligned}
$$

The $\mathrm{RI}$ of $\mathrm{SO}_{2}$ at $25^{\circ} \mathrm{C}$ is 1.3396 , which is placed in eight elliptical cores. When the sensor senses the gas, the light will confine in the $0.8 \mu \mathrm{m}$ to $1 \mu \mathrm{m}$ wavelength, and the sensitivity is improved from the minimum wavelength. In this proposed gas sensor, the output is obtained, where the light is confined in the core area and produces the best result. The light which is not contained in the core area is called confinement loss. The light confinement in the core area for the V-PCF sensor and H-PCF sensor is shown in figures $3 \mathrm{a}$ and $3 \mathrm{~b}$.

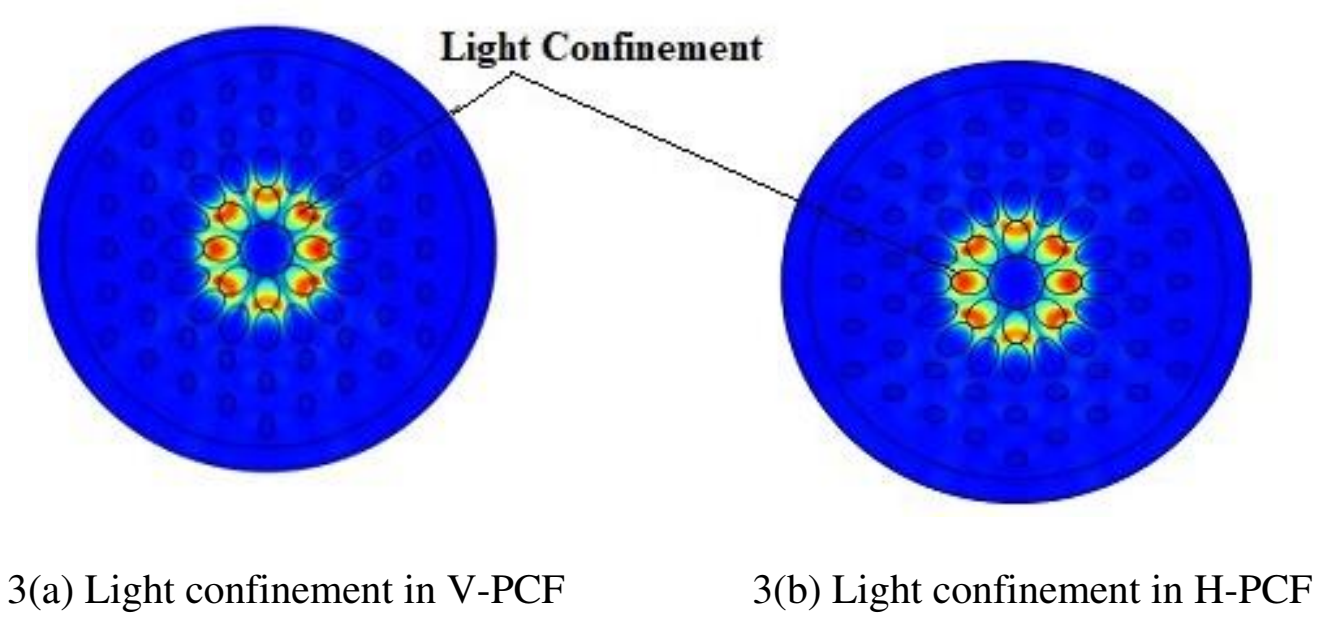

Fig. 3. Light confinement of V-PCF and H-PCF gas sensor

The simulated output of both the horizontal and vertical PCF gas sensors is compared in Table 1. A very low confinement loss of 5.93E-04 dB is attained for the V-PCF sensor and 8.94E-04 of H-PCF. The attenuation for the V-PCF sensor is only $1.1865 \mathrm{~dB} / \mathrm{Km}$, and the H-PCF sensor's value is $4.18 \mathrm{~dB} / \mathrm{Km}$. Comparatively, the attenuation of the V-PCF sensor is good. The V-PCF sensor's relative sensitivity is $59.34 \%$, and it is better than the horizontal sensitivity of $58.35 \%$. The value of the effective area is nearly 
equal for the vertical and H-PCF sensor. This table concludes that, when compared to the H-PCF sensor, the results of the V-PCF sensor are good.

Table 1. Comparison of the proposed vertical and H-PCF sensors

\begin{tabular}{|l|c|c|c|c|}
\hline $\begin{array}{c}\text { Proposed } \\
\text { Sensors }\end{array}$ & $\begin{array}{c}\text { Confineme } \\
\mathbf{n t} \\
\mathbf{L o s s} \\
(\mathbf{d B} / \mathbf{m})\end{array}$ & $\begin{array}{c}\text { Attenuati } \\
\text { on } \\
(\mathbf{d B} / \mathbf{K m})\end{array}$ & $\begin{array}{c}\text { Relative } \\
\text { Sensitivity } \\
(\boldsymbol{\%})\end{array}$ & $\begin{array}{c}\text { Effective } \\
\mathbf{a r e a}\left(\boldsymbol{\mu m}^{2}\right)\end{array}$ \\
\hline $\begin{array}{l}\text { V-PCF } \\
\text { sensor }\end{array}$ & $5.93 \mathrm{E}-04$ & 1.1865 & 59.34 & 4.61 \\
\hline $\begin{array}{l}\text { H-PCF } \\
\text { sensor }\end{array}$ & $8.94 \mathrm{E}-04$ & 4.18 & 58.92 & 4.62 \\
\hline
\end{tabular}

\section{Results and Discussions}

To investigate further, different PML values for V-PCF and H-PCF are analyzed. The different PML values are $0.5 \mu \mathrm{m}, 1 \mu \mathrm{m}$, and $1.5 \mu \mathrm{m}$. The purpose of the PML is to avoid the scattering of light away from cladding. In the second stage, the V-PCF gas sensor's elliptical constant is compared with a different elliptical constant. In the third stage, the core of the V-PCF sensor is compared with other core elliptical constant.

\subsection{Effect of change of PML in the V-PCF and H-PCF gas sensor}

The proposed V-PCF gas sensor has the $1^{\text {st }}$ and $2^{\text {nd }}$ cladding elliptical constant of 0.75 ; the inner cladding has an elliptical constant of 0.625 , and the core elliptical constant of 0.714 . Different PML values such as $0.5 \mu \mathrm{m}, 1 \mu \mathrm{m}$ and $1.5 \mu \mathrm{m}$ are used, and these PML values are compared with the PML of the V-PCF gas sensor as shown in figure $4(\mathrm{a}-\mathrm{f})$. The PML value of the proposed method is $0.5 \mu \mathrm{m}$. The relative sensitivity and useful mode for these different PML values are analyzed. Different PML values such as $0.5 \mu \mathrm{m}, 1 \mu \mathrm{m}$, and $1.5 \mu \mathrm{m}$ are used in vertical and horizontal cladding outer two layers, respectively. 


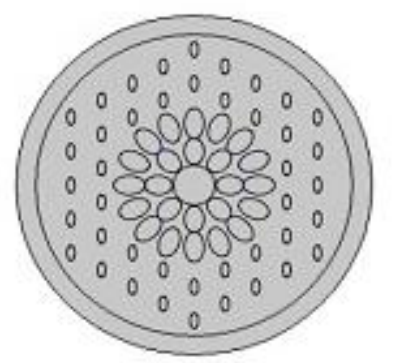

(a)

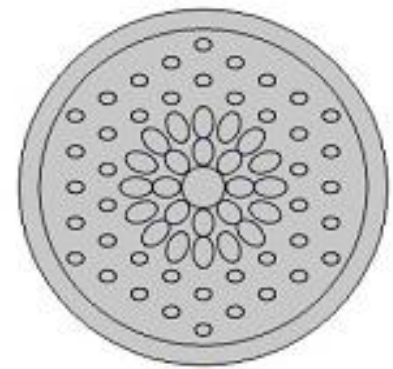

(d)

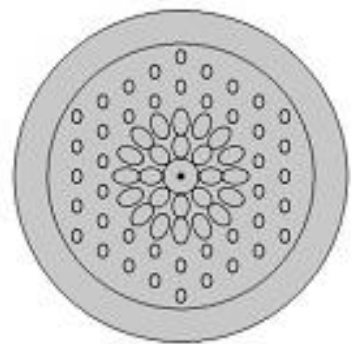

(b)

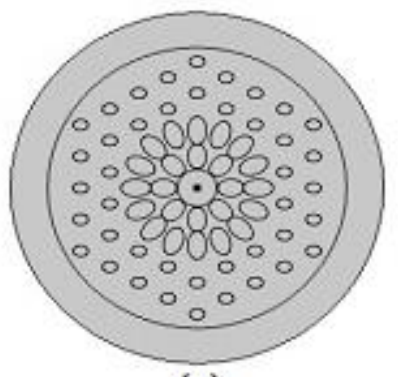

(e)

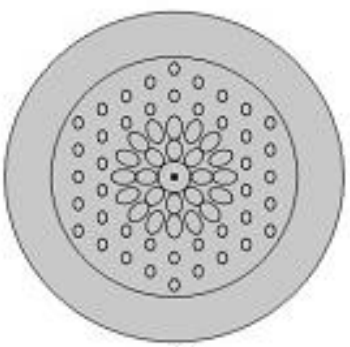

(c)

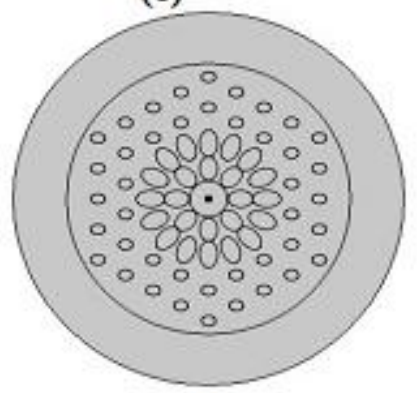

(f)

Fig. 4. Structure of: (a) V-PCF sensor with $0.5 \mu \mathrm{m}$ PML (b) $1 \mu \mathrm{m}$ PML (c) $1.5 \mu \mathrm{m}$ PML (d) H-PCF

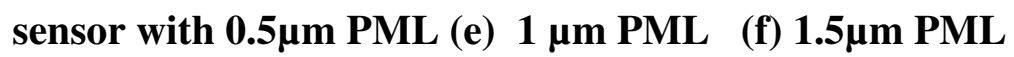

The sensitivity in percentage for V-PCF and H-PCF with the PML of $0.5 \mu \mathrm{m}, 1 \mu \mathrm{m}$, and $1.5 \mu \mathrm{m}$ are given in Table 2 for the wavelength ranges from $0.8 \mu \mathrm{m}$ to $1 \mu \mathrm{m}$. In this PCF gas sensor, the light confinement takes place only between $0.8 \mu \mathrm{m}-1 \mu \mathrm{m}$, and above $1 \mu \mathrm{m}$, the light will be scattered, and it is difficult to confine light above $1 \mu \mathrm{m}$.

Table 2. Relative sensitivity for V-PCF and H-PCF Sensors

\begin{tabular}{|c|c|c|c|c|c|c|}
\hline \multirow[t]{2}{*}{ Wavelength $(\mu \mathrm{m})$} & \multicolumn{3}{|c|}{$\begin{array}{l}\text { Sensitivity for PML layer thickness } \\
\text { in V-PCF sensor }\end{array}$} & \multicolumn{3}{|c|}{$\begin{array}{l}\text { Sensitivity for PML layer thickness in H- } \\
\text { PCF Sensor }\end{array}$} \\
\hline & $0.5 \mu \mathrm{m}$ & $1 \mu \mathrm{m}$ & $1.5 \mu \mathrm{m}$ & $0.5 \mu \mathrm{m}$ & $1 \mu \mathrm{m}$ & $1.5 \mu \mathrm{m}$ \\
\hline 0.8 & 29.26 & 28.67 & 28.77 & 28.90 & 28.73 & 28.06 \\
\hline 0.82 & 29.51 & 29.80 & 29.54 & 29.07 & 29.27 & 29.53 \\
\hline 0.84 & 30.63 & 30.20 & 29.74 & 29.77 & 30.07 & 29.76 \\
\hline 0.86 & 37.63 & 36.89 & 37.53 & 36.58 & 37.12 & 36.49 \\
\hline 0.9 & 48.87 & 48.82 & 48.47 & 48.90 & 48.95 & 48.78 \\
\hline 0.92 & 49.13 & 49.55 & 49.12 & 49.34 & 49.45 & 49.37 \\
\hline 0.94 & 54.25 & 54.11 & 54.18 & 54.21 & 54.15 & 54.15 \\
\hline 0.96 & 56.77 & 57.29 & 56.64 & 56.70 & 56.41 & 56.49 \\
\hline 0.98 & 57.84 & 58.35 & 57.88 & 57.67 & 58.07 & 57.89 \\
\hline 1 & 59.34 & 0.11 & 0.00 & 58.92 & 0.11 & 0.01 \\
\hline
\end{tabular}


From Figure 5a, it is found that the relative sensitivity curve for $\mathrm{V}$-PCF of $0.5 \mu \mathrm{m}$ PML is increasing with increasing wavelength. For this $0.5 \mu \mathrm{m}$ PML, the maximum relative sensitivity of $59.344 \%$ is achieved at $1 \mu \mathrm{m}$ wavelength. Further, different PML values for the horizontal outer cladding are analyzed. For horizontal $0.5 \mu \mathrm{m}$, the relative sensitivity curve is drawn, and it is increasing concerning wavelength. The maximum sensitivity of $58.53 \%$ is achieved for the wavelength of $1 \mu \mathrm{m}$. For $1 \mu \mathrm{m}$ and $1.5 \mu \mathrm{m}$ PML, the relative sensitivity decreases at $1 \mu \mathrm{m}$ wavelength. It happens because the light is not confined to the core region, and it is scattered over the cladding layer. As the PML value increases, the relative sensitivity decreases. The maximum sensitivity of $59.344 \%$ and $58.53 \%$ at $1 \mu \mathrm{m}$ wavelength is achieved for V-PCF and H-PCF with $0.5 \mu \mathrm{m}$ PML.

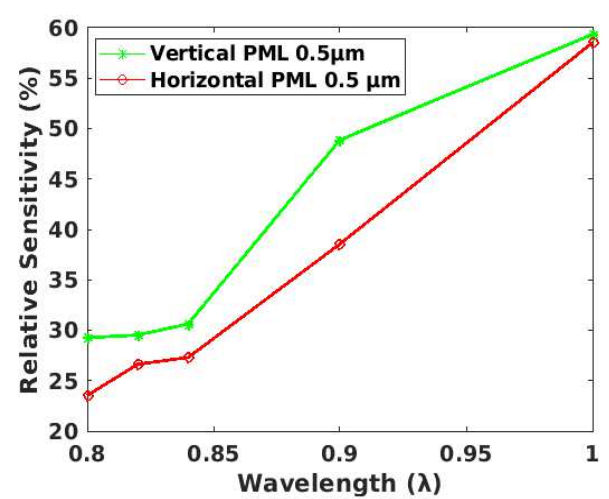

5(a) Sensitivity for V-PCF $0.5 \mu \mathrm{m}$ PML

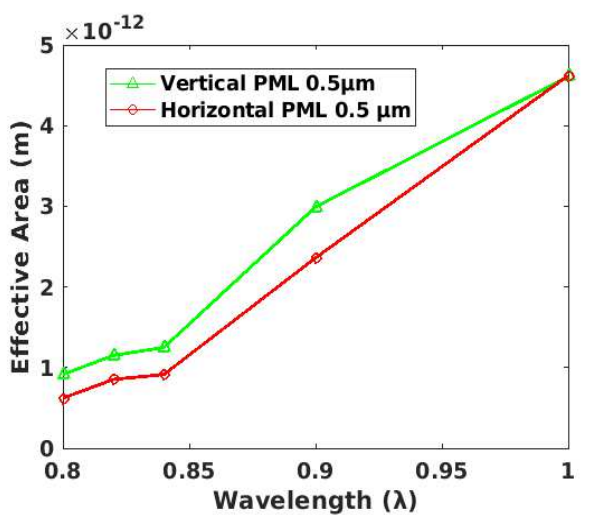

5(b) Effective area for V-PCF 0.5 $\mu \mathrm{m}$ PML

\section{Fig. 5. Sensitivity profile and effective-area of V-PCF and H-PCF Sensors for 0.5 PML}

From the relative sensitivity curve, it is analyzed that the V-PCF's sensitivity of $0.5 \mu \mathrm{m}$ PML is high compared with the H-PCF of $0.5 \mu \mathrm{m}$ PML. The sensitivity curve for V-PCF for $0.5 \mu \mathrm{m}$ PML is linear, and it is far better than the H-PCF of the $0.5 \mu \mathrm{m}$ PML curve. For V-PCF of $0.5 \mu \mathrm{m}$, the effective area increases with increasing wavelength. From the figure $5 \mathrm{~b}$, it is inferred that the effective area for V-PCF and H-PCF outer cladding for $0.5 \mu \mathrm{m}$ PML is growing linearly. The effective-area reaches its maximum at $4.61 \mu \mathrm{m}^{2}$. Using the V-PCF sensor with 0.5 $\mu \mathrm{m}$ PML as a base, further analysis is done, and they are explained in Section 3.2 and 


\subsection{The effect of changing the inner cladding}

In this analysis, the two best values of the inner cladding elliptical constant are 0.75 [a-semi-axis of $0.8 \mu \mathrm{m}$ and $\mathrm{b}$-semi-axis $=0.6 \mu \mathrm{m}]$ and $0.65[\mathrm{a}$-semi-axis $=0.85 \mu \mathrm{m}, \mathrm{b}$-semi-axis $=0.55 \mu \mathrm{m}]$ and Fig.6 shows light confinement of the electromagnetic signal in the design of two different $3^{\text {rd }}$ (inner) cladding. These two elliptical constants are compared to the proposed V-PCF gas sensor with an elliptical constant of 0.625 [asemi-axis $=0.8 \mu \mathrm{m}, \mathrm{b}$-semi-axis $=0.5 \mu \mathrm{m}]$. The sensitivity of the V-PCF gas sensor is observed to be the best. The elliptical constant of 0.625 produces the best result when compared to others, because its size is small and places it correctly in the center between the core and the outer layer. In order to achieve the best result, two things need to be considered, the size of the inner cladding should be larger than the outer cladding, and the inner cladding value should be placed in the center between the core and the outer cladding. If the size of the inner cladding increases or decreases, the sensitivity decreases.

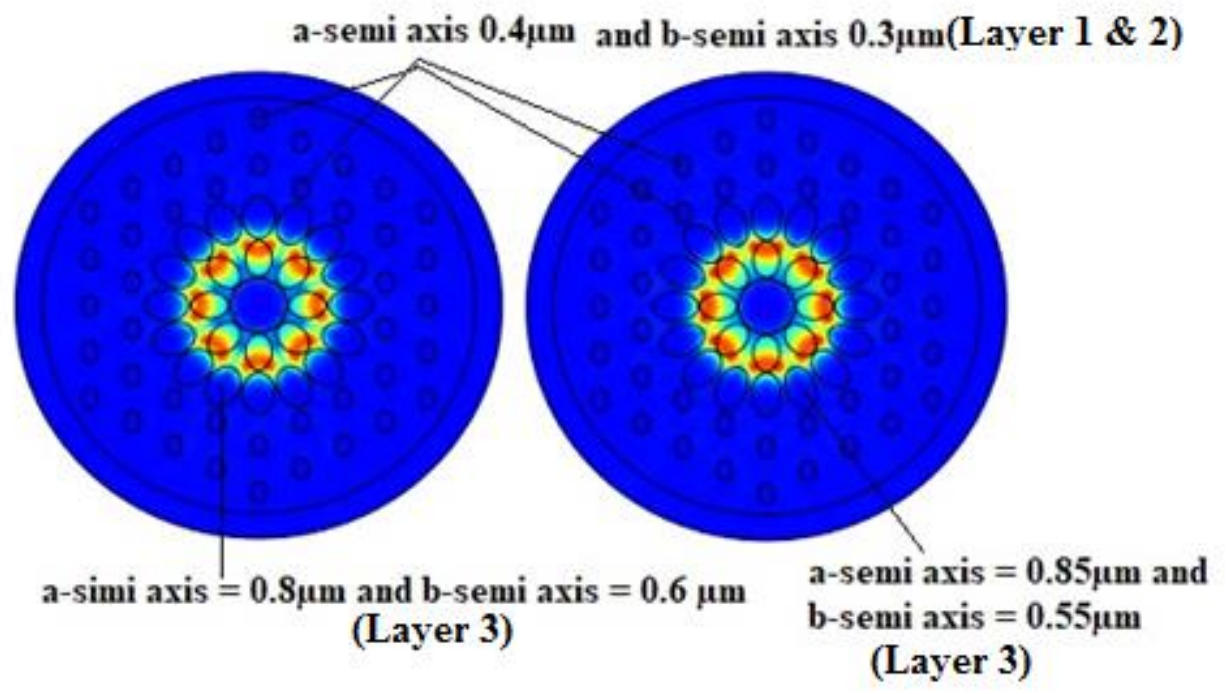

Fig. 6. Light confinement for the two different $3^{\text {rd }}$ layer (inner) cladding 


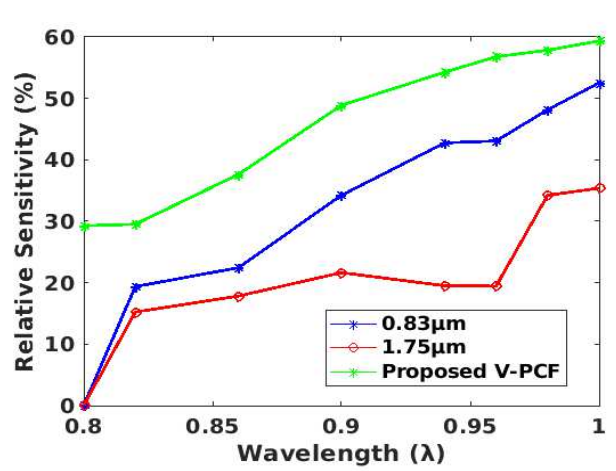

(a) Sensitivity of inner cladding

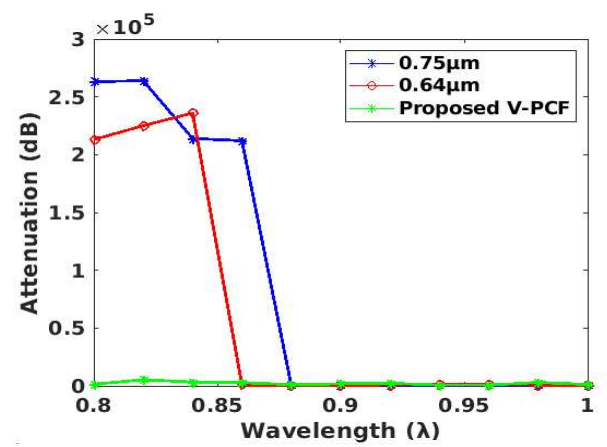

(c) Attenuation of inner cladding

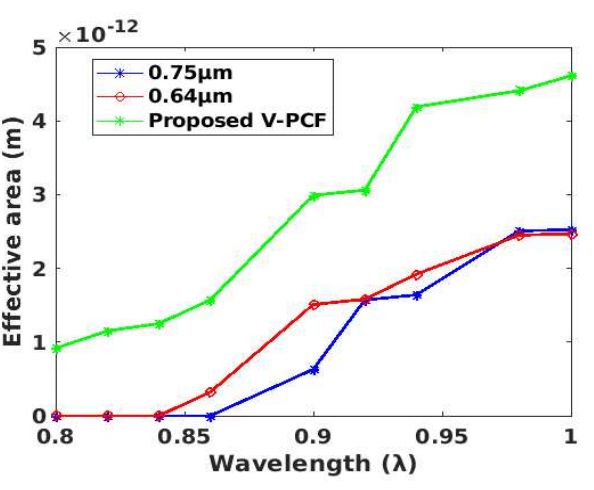

(b) Effective area of the inner cladding

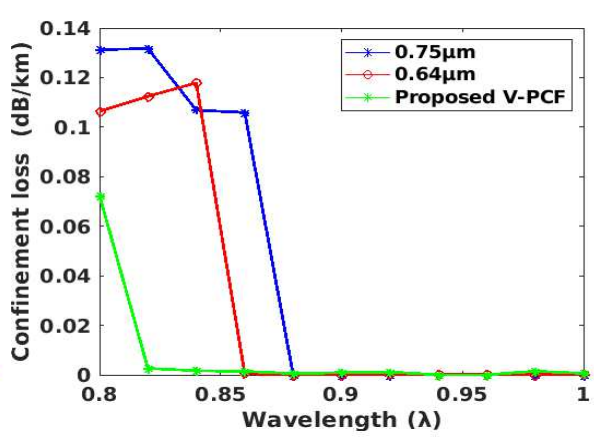

(d) Confinement loss of inner cladding

Fig. 7. Analysis of various sensor parameters for the different inner cladding

The relative sensitivity and sufficient area for the different inner cladding layers are drawn as given in figure 7 and compared to the proposed gas sensor. The sensitivity and functional area of the proposed V-PCF gas sensor has been found to increase to the maximum wavelength. It is analyzed that as the wavelength increases, the attenuation level is significantly lower and reaches almost zero as the wavelength increases to its maximum value. The confinement loss is considerably less for the proposed gas sensor and is almost zero as the wavelength propagates to full value. Confinement loss decreases due to an increase in the CoreCladding Index. The relative sensitivity and mode area for different inner cladding layers are $38.551 \%, 37.942$ $\%, 2.54 \mu \mathrm{m}^{2}$, and $2.47 \mu \mathrm{m}^{2}$, respectively.

\subsection{The effect of changing the core elliptical constant}

Two different elliptical cores are considered in this design. For this core, the elliptical constant is 0.83 and 1.75. This value is compared to the proposed V-PCF gas sensor with an elliptical constant of 0.714 . The 
light confinement for the two designs is shown in figure 8. If this value is increased, the sensitivity will decrease, and if the core elliptical constant decreases, the sensitivity will be almost zero. The sensitivity of the proposed V-PCF gas sensor is increasing linearly. It reaches a maximum of $1 \mu \mathrm{m}$ and the remaining two values are compared to a maximum sensitivity of $52.523 \%$ and $35.38 \%$, which is lower than the proposed VPCF gas sensor. The proposed sensor's effective mode area is $4.61 \mu \mathrm{m}^{2}$, which is greater than $3.60 \mu \mathrm{m}^{2}$ and $1.56 \mu \mathrm{m}^{2}$. Attenuation is reduced and limited, resulting in reduced confinement loss for the proposed V-PCF gas sensor.

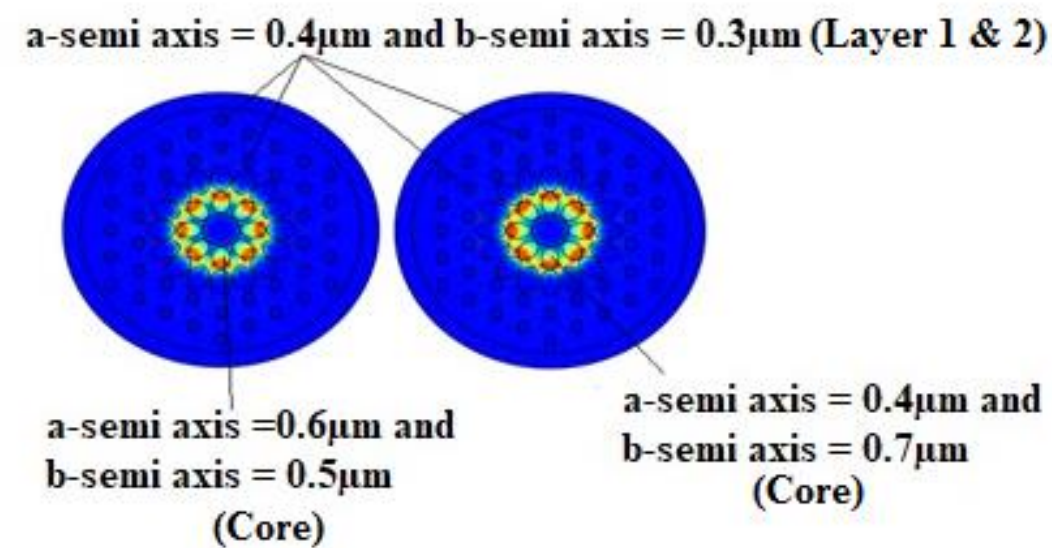

Fig. 8. Light confinement for different core values in V-PCF

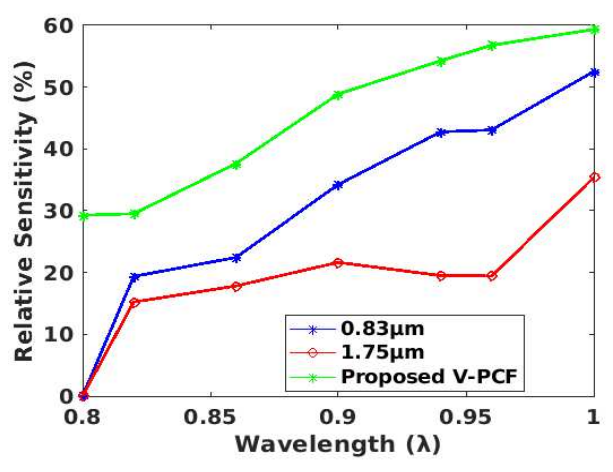

(a) Sensitivity of different core

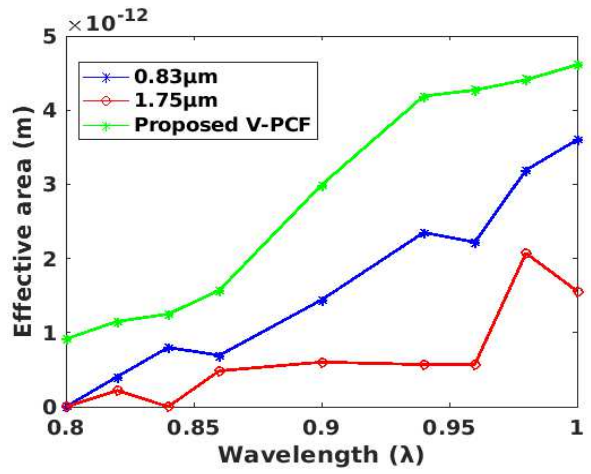

(b) Effective area of other core 


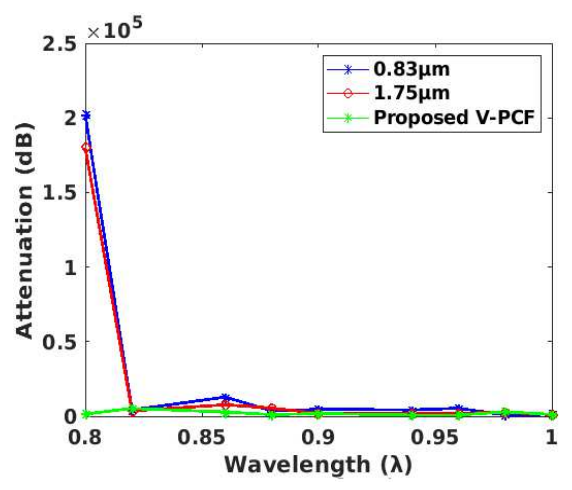

(c) Attenuation of different core

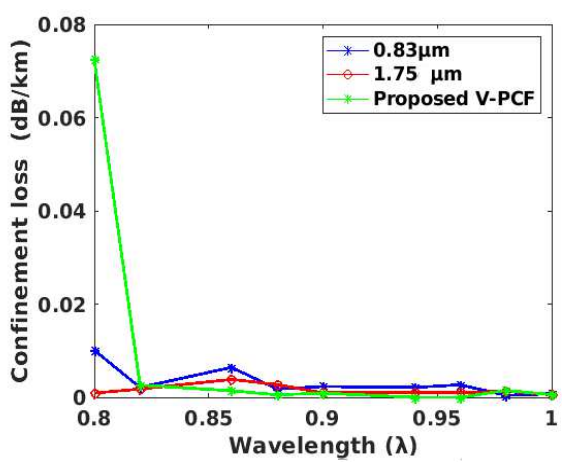

(d) ) Confinement loss of different core

Fig. 9. Graph for the different core elliptical constant

In the first stage, different PML values for V-PCF and H-PCF are considered. For these different PML, the V-PCF gas sensor of $0.5 \mu \mathrm{m}$ gives the best result. The $0.5 \mu \mathrm{m}$ PML V-PCF gas sensor is compared with the inner cladding layer elliptical constant and different vertical core elliptical constant. In figure 9, the comparison of the sensitivity, useful mode, attenuation, and confinement-loss concerning wavelength are drawn using the software. It is found that the proposed method produces good sensitivity, less attenuation, and loss confinement loss for $\mathrm{SO}_{2}$ at $25^{\circ} \mathrm{C}$, and the comparison table of this best design is shown in table 3 .

Table 3. Analysis of the proposed V-PCF gas sensor for 0.5 $\mu \mathrm{m}$ PML

\begin{tabular}{|c|c|c|c|c|c|c|}
\hline \multirow[b]{2}{*}{ S.No } & \multirow[b]{2}{*}{ Structure } & \multirow[b]{2}{*}{$\begin{array}{c}\text { Core } \\
\text { diameter } \\
(\mu \mathrm{m})\end{array}$} & \multicolumn{2}{|c|}{$\begin{array}{c}\text { Cladding diameter } \\
(\mu \mathrm{m})\end{array}$} & \multirow[b]{2}{*}{$\begin{array}{l}\text { Sensitivity } \\
\text { at } 1 \mu \mathrm{m}\end{array}$} & \multirow[b]{2}{*}{$\begin{array}{l}\text { Effective } \\
\text { area } \\
\left(\mu \mathrm{m}^{2}\right)\end{array}$} \\
\hline & & & $\begin{array}{l}\text { Outer } \\
\text { cladding } \\
\text { layers1 } \\
\& 2\end{array}$ & $\begin{array}{c}\text { Inner } \\
\text { Cladding } \\
3^{\text {rd }} \text { layer }\end{array}$ & & \\
\hline 1 & $\begin{array}{l}\text { V-PCF } \\
\text { Sensor }\end{array}$ & 0.71 & 0.75 & 0.625 & $59.344 \%$ & 4.61 \\
\hline 2 & $\begin{array}{l}\text { V-PCF } \\
\text { Sensor }\end{array}$ & 0.71 & 0.75 & 0.75 & $38.551 \%$ & 2.52 \\
\hline 3 & $\begin{array}{l}\text { V-PCF } \\
\text { Sensor }\end{array}$ & 0.71 & 0.75 & 0.64 & $37.942 \%$ & 2.47 \\
\hline 4 & $\begin{array}{l}\text { V-PCF } \\
\text { Sensor }\end{array}$ & 0.83 & 0.75 & 0.625 & $52.523 \%$ & 3.6 \\
\hline 5 & $\begin{array}{l}\text { V-PCF } \\
\text { Sensor }\end{array}$ & 1.75 & 0.75 & 0.625 & $35.380 \%$ & 1.56 \\
\hline
\end{tabular}

Note: The core, inner, and outer cladding layers are represented in terms of elliptical constant. 


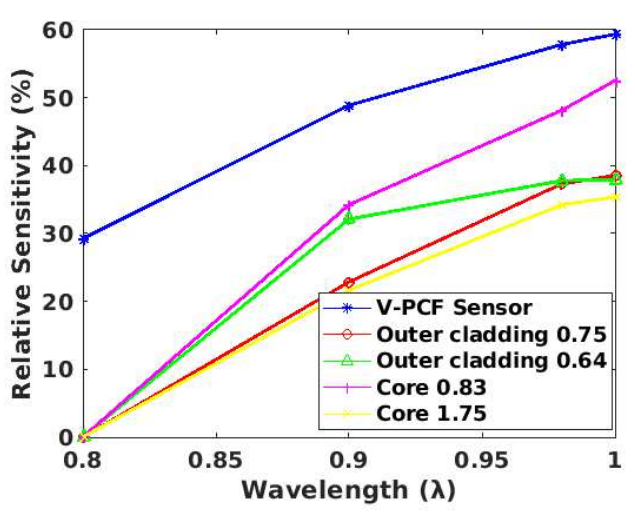

(a)

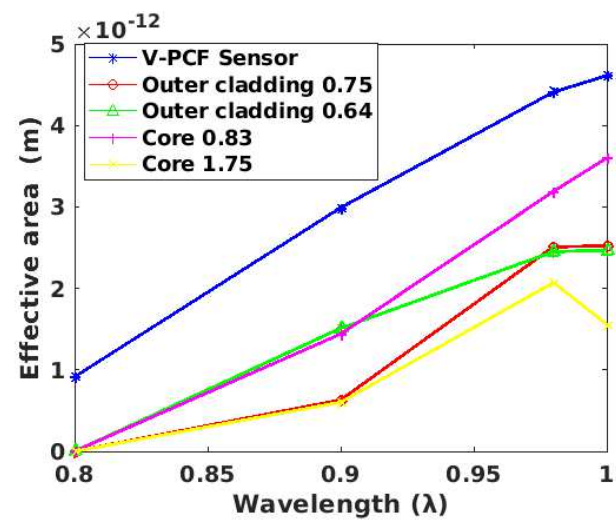

(b)

Fig. 10. Wavelength vs. (a) Relative sensitivity of different cladding and core (b) Effective area of varying cladding and core

The comparative graph shown in Figure 10 shows a clear picture of the sensitivity and the mode area. The proposed V-PCF gas sensor achieves a sensitivity of $59.34 \%$ and a mode area of $4.61 \mu \mathrm{m}^{2}$. Table 4 shows the comparison of the proposed sensors (V-PCF \& H-PCF) with the different existing gas sensors and it is understood that the sensitivity of the proposed V-PCF sensor is correct to detect $\mathrm{SO}_{2}$ using a hexagonal system.

Table 4. Sensitivity comparison of the proposed PCF with other related works

\begin{tabular}{|c|l|c|c|}
\hline S.No & \multicolumn{1}{|c|}{ PCF Sensors } & Sensitivity & Reference \\
\hline 1 & V- PCF sensor & $59.344 \%$ & -- \\
\hline 2. & H-PCF sensor & $58.34 \%$ & -- \\
\hline 2 & $\begin{array}{l}\text { Microstructured } \mathrm{G}_{\mathrm{e}} \mathrm{O}_{2} \text { doped silica } \\
\text { PCF [17] }\end{array}$ & $16.88 \%$ & 2015 \\
\hline 3 & Hybrid PCF gas sensor [18] & $15.67 \%$ & 2016 \\
\hline 4 & Index-guiding PCF sensor [19] & $32.99 \%$ & 2013 \\
\hline 5 & Hexagonal porous PCF sensor [20] & $42.27 \%$ & 2015 \\
\hline 6 & PCF based gas sensor [21] & $53.07 \%$ & 2016 \\
\hline 7 & Spiral PCF sensor [22] & $55.10 \%$ & 2017 \\
\hline 8 & $\begin{array}{l}\text { Porous core PCF sensors to detect } \\
\mathrm{H}_{2} \mathrm{~S} \text { gas [23] }\end{array}$ & $\begin{array}{c}0.268 \% / \\
\mathrm{ppm}\end{array}$ & 2019 \\
\hline 9 & $\begin{array}{l}\text { High sensitivity } \mathrm{H}_{2} \mathrm{~S} \text { gas sensor } \\
\text { using a combination of graphene } \\
\text { properties [24] }\end{array}$ & $\begin{array}{c}1.2 \times 10^{4} \mathrm{~nm} \\
/ \mathrm{RIU}\end{array}$ & 2020 \\
\hline 10 & $\begin{array}{l}\text { PCF Mach-Zehnder interferometer } \\
\text { to detect } \mathrm{H}_{2} S \text { gas [25] }\end{array}$ & $\begin{array}{c}26.62 \mathrm{pm} \\
\mathrm{ppm}^{-1}\end{array}$ & 2020 \\
\hline
\end{tabular}




\section{Conclusion}

The primary focus of this paper is to investigate the relative sensitivity, user mode, and confinement loss of the proposed V-PCF gas sensor for $\mathrm{SO}_{2}$ detection applications. In this method, different cladding and a single core layer are used. The V-PCF gas sensor is analyzed for different PMLs, other cores and additional claddings. The proposed V-PCF provides the best relative sensitivity of $59.344 \%$. $\mathrm{SO}_{2}$ can be detected with high sensitivity using this proposed PCF sensor. $\mathrm{SO}_{2}$ is released from volcanic activity and eruptions into the air. If a vapor at $25^{\circ} \mathrm{C}$ is released into the air, $\mathrm{SO}_{2}$ will only exist as a gas in the atmosphere. $\mathrm{These}^{\mathrm{SO}} \mathrm{S}_{2}$ in the air will cause asthma and even cancer, so this proposed PCF is highly useful in biomedical applications.

Author Contributions: M.N.: Writing—original draft, supervision, writing-review and editing. E.C.: Writing — original draft, supervision, writing — review and editing. P.K.: Writing—review and editing. All authors have read and agreed to the published version of the manuscript.

Conflicts of Interest: The authors declare no conflict of interest.

Funding: This research did not receive any specific grant from funding agencies in the public, commercial, or not-for-profit sectors.

Code availability: Not Applicable

Availability of data and material: The data presented in this study are available on request from the corresponding author. 


\section{References}

[1] Jean G. French et al., The Effect of Sulfur Dioxide and Suspended Sulfates on Acute Respiratory Disease, Pages 129-133 | Received 28 Nov 1972, Accepted 11 Apr 1973, Published online: 22 Apr (2013)

[2] Md. Bellal Hossain et al. "Optimized Hexagonal Photonic Crystal Fiber Sensor for Glucose sensing" Advances in Research, AIR, 13(3): (2018) pp 1-7.

[3] S. Asaduzzaman, K. Ahmed Proposal of a gas sensor with high sensitivity, birefringence, and nonlinearity for air pollution monitoring Sens Bio-Sens Res, 10 (2016), pp. 20-26.

[4] M. Morshed, M.I. Hassan, T.K. Roy, M.S. Uddin, S.A. RazzakMicrostructure core photonic crystal fiber for gas sensing applications Appl Opt, 54 (29) (2015), pp. 8637-8643

[5] B.K. Paul, K. Ahmed, S. Asaduzzaman, M.S. Islam Folded cladding porous shaped photonic crystal fiber with high sensitivity in optical sensing applications: design and analysis Sens Bio-Sens Res, 12 (2017), pp. $36-42$

[6] Ademgil, Huseyin, and Shyqyri Haxha. "PCF based sensor with high sensitivity, high birefringence and low confinement losses for liquid analyte sensing applications." Sensors 15.12 (2015): 31833-31842

[7] M.S. Islam, B.K. Paul, K. Ahmed, S. Asaduzzaman, M.I. Islam, S. Chowdhury, et al. Liquid-infiltrated photonic crystal fiber for sensing purpose: design and analysis Alex Eng J (2017)

[8] N. Ayyanar, D. Vigneswaran, M. Sharma, M. Sumathi, M.M. Rajan, S. Konar Hydrostatic pressure sensor using high birefringence photonic crystal fibers IEEE Sens J, 17 (3) (2017), pp. 650-656

[9] Chen, D., Vincent Tse, M.L. and Tam, H.Y. (2010) Optical Properties of Photonic Crystal Fibers with a Fiber Core of Arrays of Subwavelength Circular Air Holes: Birefringence and Dispersion. Progress in Electromagnetics Research, 105, 193-212. 
[10]Wu, B.Q., Lu, Y., Hao, C.J., Duan, L.C., Luan, N.N., Zhao, Z.Q. and Yao, J.Q. (2013) Hollow-Core Photonic Crystal Fiber Based on C2H2 and NH3 Gas Sensor. In: Applied Mechanics and Materials, Vol. 411, Trans Tech Publications, Zürich, 1577-1580.

[11]Arif, MdFaizul Huq, Kawsar Ahmed, Sayed Asaduzzaman, and Md Abul Kalam Azad. Design and optimization of photonic crystal fiber for liquid sensing applications. Photonic Sensors. 2016;6(3):279288.

[12]Hossain, MdBellal, Abdullah Al-Mamun Bulbul, Md Abdul Mukit, EtuPodder. Analysis of optical properties for square, circular and hexagonal photonic crystal fiber. Optics and Photonics Journal. 2017;7(11):235.

[13] Ademgil, Huseyin. Highly sensitive octagonal photonic crystal fiber based sensor. Optik-International Journal for Light and Electron Optics. 2014;125(20): 6274-6278.

[14]Akowuah, Emmanuel K., Terry Gorman, HuseyinAdemgil, ShyqyriHaxha, Gary K. Robinson, Jenny V. Oliver. Numerical analysis of a photonic crystal fiber for biosensing applications. IEEE Journal of Quantum Electronics. 2012;8(11):1403-1410.

[15]Park, Jiyoung, Sejin Lee, Soan Kim, Kyunghwan Oh. Enhancement of chemical sensing capability in a photonic crystal fiber with a hollow high index ring defect at the center. Optics Express. 2011;19(3): 1921-1929.

[16]Kim, Soeun, Yong Soo Lee, Chung Ghiu Lee, Yongmin Jung, Kyunghwan Oh. Hybrid SquareLattice Photonic Crystal Fiber with Broadband Single-Mode Operation, High Birefringence, and Normal Dispersion. Journal of the Optical Society of Korea. 2015;19(5):449-455.

[17]Ahmed, Kawsar, Monir Morshed. Design and numerical analysis of microstructured-core octagonal photonic crystal fiber for sensing applications. Sensing and Bio-Sensing Research. 2016;7:1-6. 
[18] Morshed et al, Enhancement of the sensitivity of gas sensor based on microstructure optical fiber, Photonic Sens 5(4) 2015: 312-320

[19]Asaduzzaman et al, Design of Simple Structure Gas Sensor Based on Hybrid Photonic Crystal Fiber, (CSJ) 37(3) 2016; 187-196

[20] S.Olyaee et.al, design and optimization of index guiding Photonic fiber crystal gas sensor, Photonic Sens 3(2) $2013 ; 131-136$

[21]M. Morshed, M.I. Hassan, T.K. Roy, M.S. Uddin, S.A. Razzak Microstructure core photonic crystal fiber for gas sensing applications Appl Opt, 54 (29) 2015, pp. 8637-8643.

[22]S. Asaduzzaman, K. Ahmed Proposal of a gas sensor with high sensitivity,birefringence and nonlinearity for air pollution monitoring Sens Bio-Sens Res, 10 (2016), pp. 20-26

[23] M.I. Islam et.al, design of single mode spiral Photonic crystal fiber for gas sensing application, Sens. BioSens. Res. 13(1) 2017; 55-62.

[24]Jianyuan Qin et.al, Terahertz detection of toxic gas using a photonic crystal fiber, Optical Fiber Technology, November 2019, Volume 52, 101990.

[25] AfroozAfsariet.al, design of a hydrogen sulfide gas sensor based on a photonic crystal cavity using graphene, Superlattices and Microstructures, February 2020, Volume 138, 106362.

[26]Guojia Huang et.al, Hydrogen sulfide gas sensor based on titanium dioxide/amino-functionalized graphene quantum dots coated photonic crystal fiber, 3 June 2020, Journal of Physics D: Applied Physics, Volume 53, Number 32. 
Figures

\section{lst and 2nd}

Vertical air hole

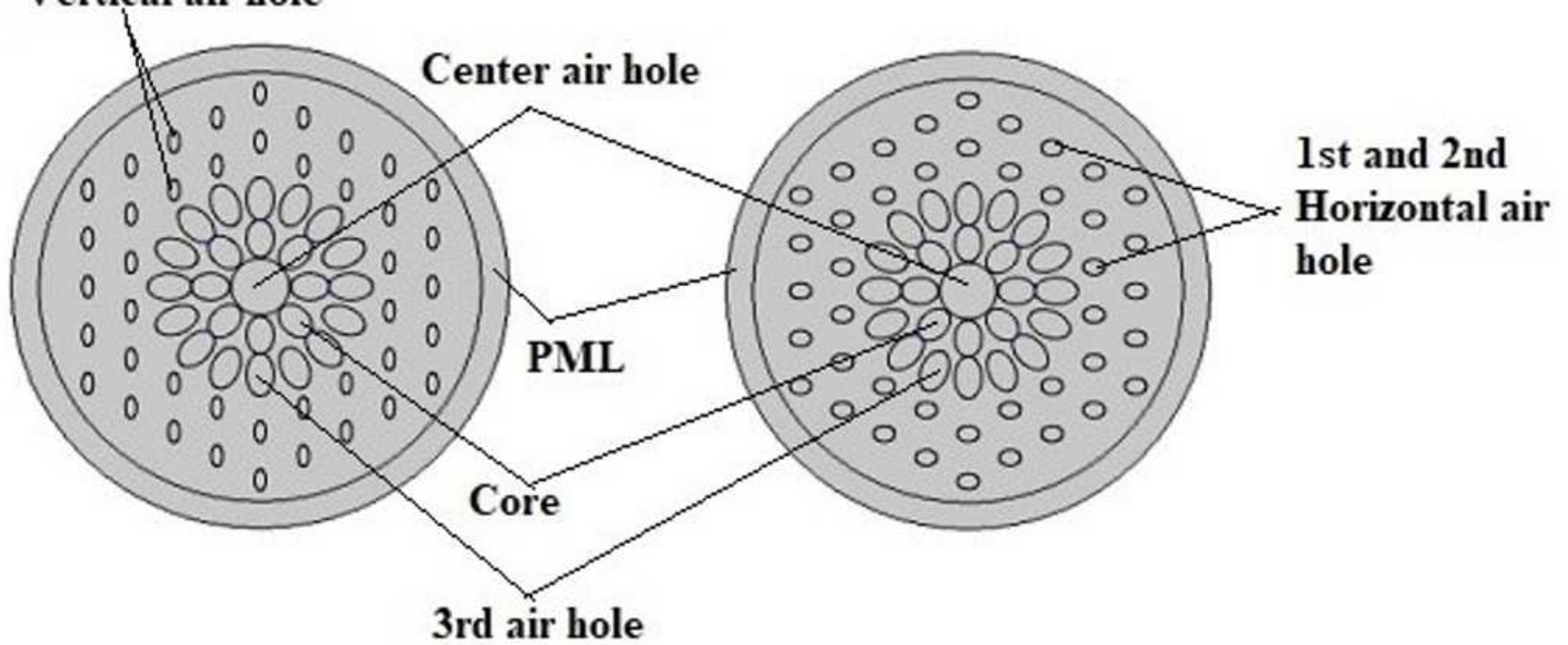

1(a) Structure of V-PCF sensor

1(b) Structure of H-PCF sensor

Figure 1

PCF gas sensor diagram 


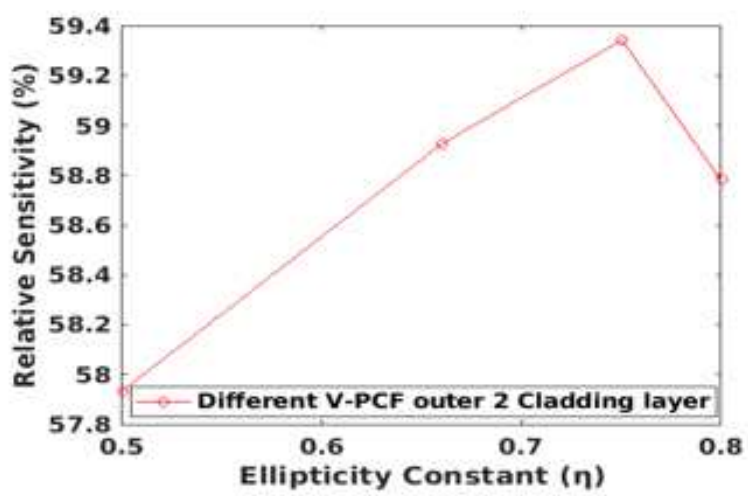

2(a) V-PCF outer cladding

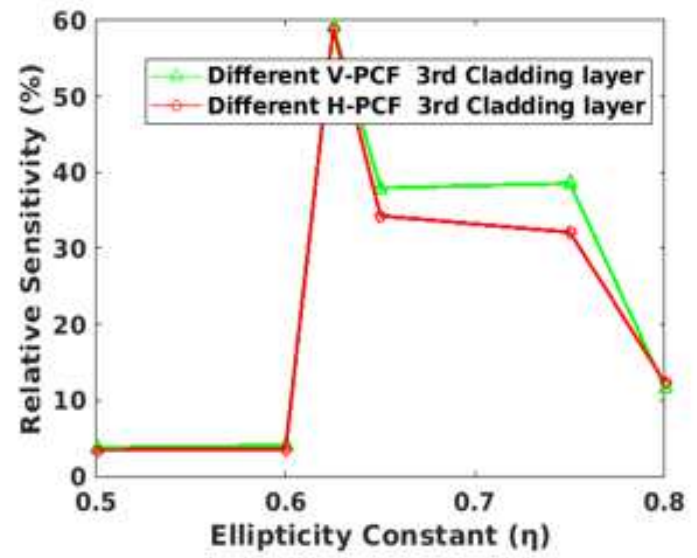

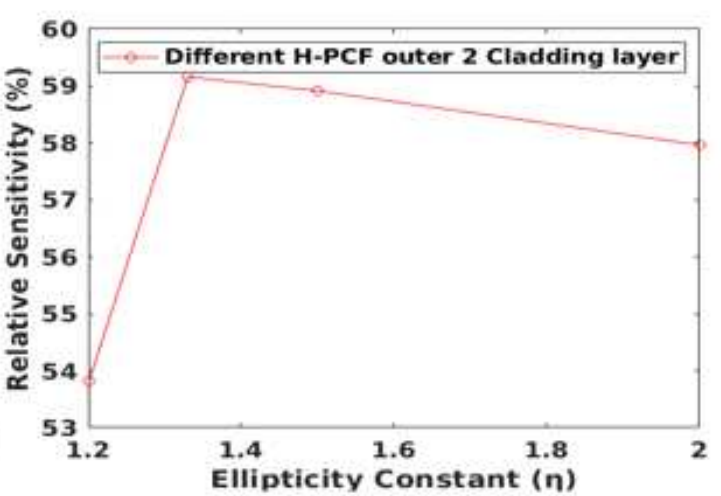

2(b) H-PCF outer cladding

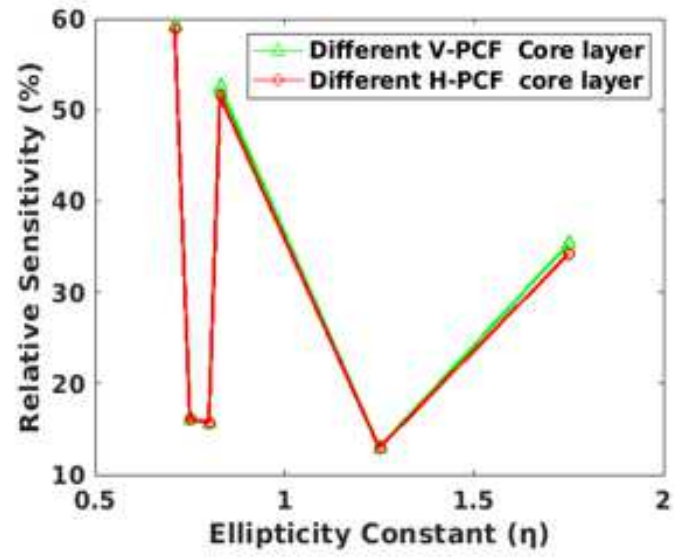

2(c) Comparison graph for inner cladding 2(d) Comparison graph for the core layer

\section{Figure 2}

Comparison graph for different elliptical constant 


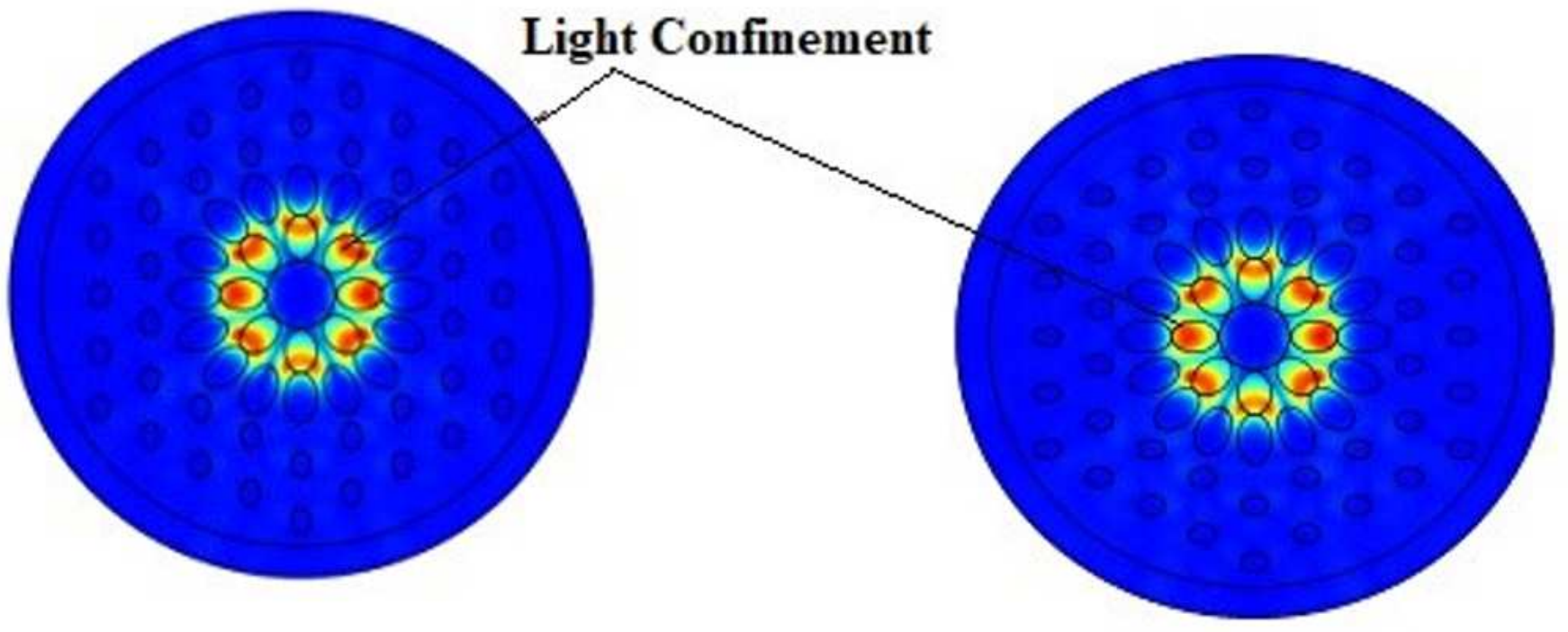

3(a) Light confinement in V-PCF

3(b) Light confinement in H-PCF

Figure 3

Light confinement of V-PCF and H-PCF gas sensor

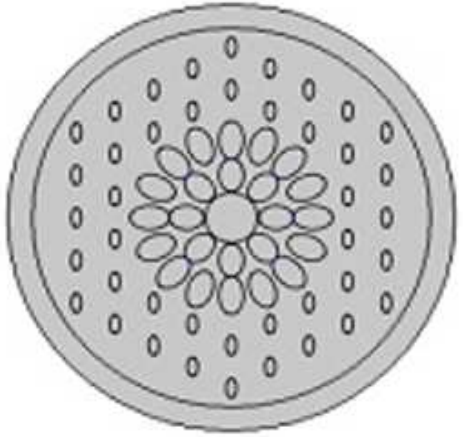

(a)

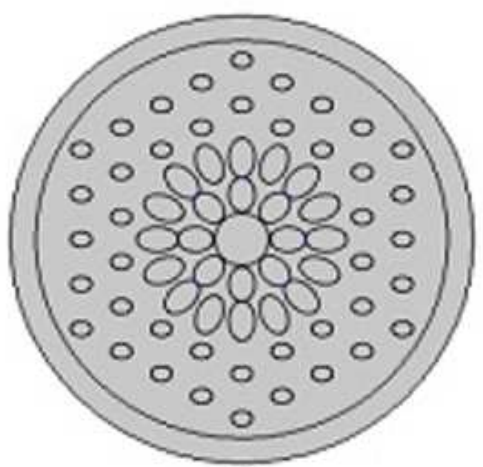

(d)

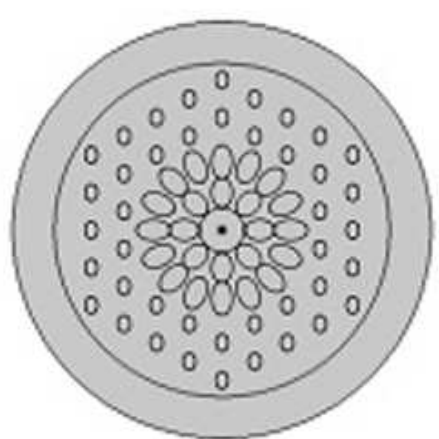

(b)

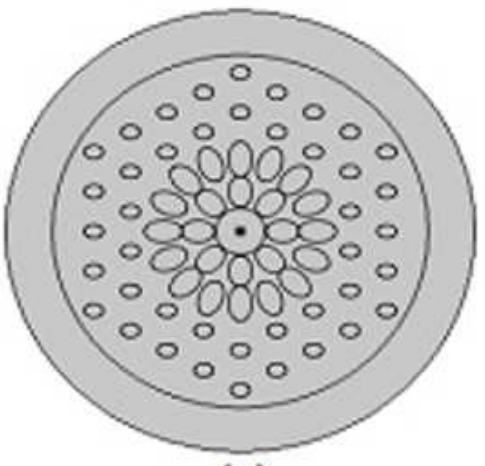

(e)

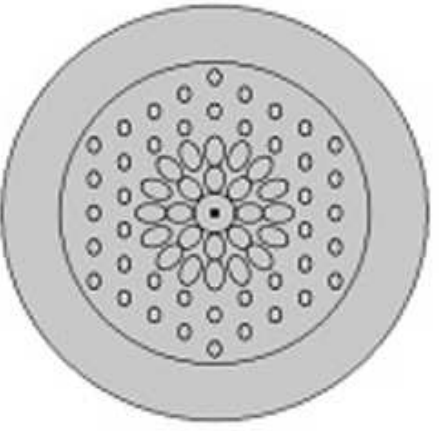

(c)

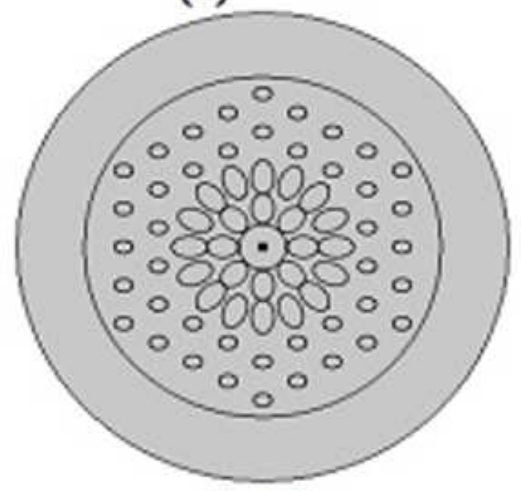

(f)

Figure 4 


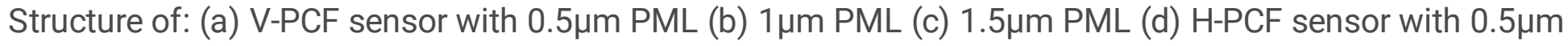
PML (e) $1 \mu \mathrm{m}$ PML (f) $1.5 \mu \mathrm{m}$ PML

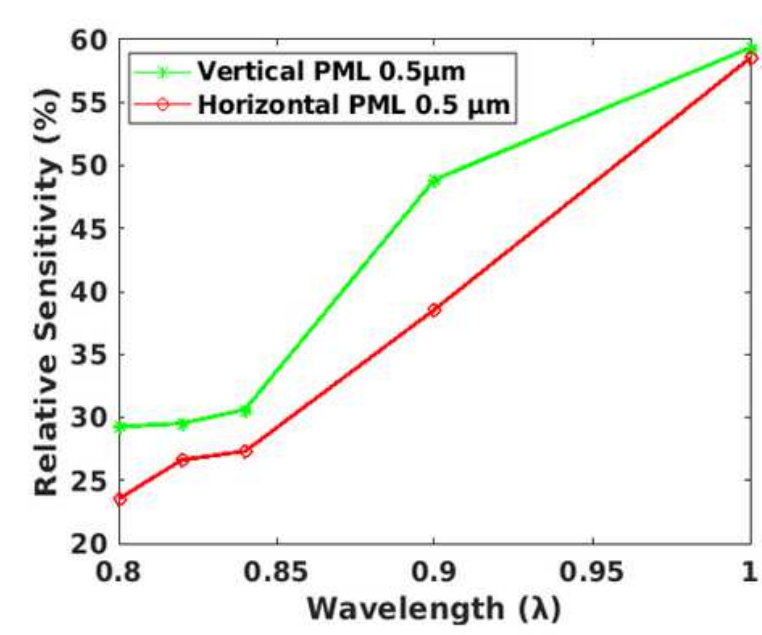

5(a) Sensitivity for V-PCF $0.5 \mu \mathrm{m}$ PML

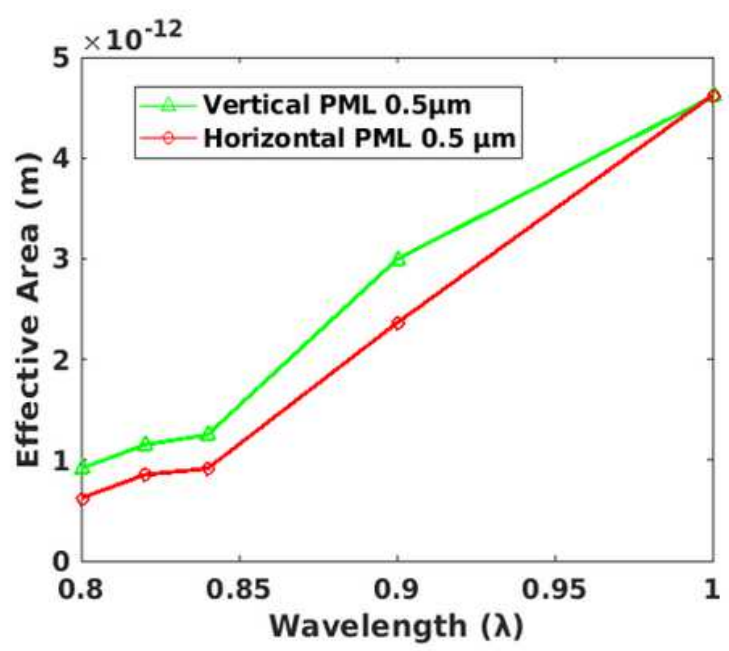

5(b) Effective area for V-PCF $0.5 \mu \mathrm{m}$ PML

\section{Figure 5}

Sensitivity profile and effective-area of V-PCF and H-PCF Sensors for 0.5 PML

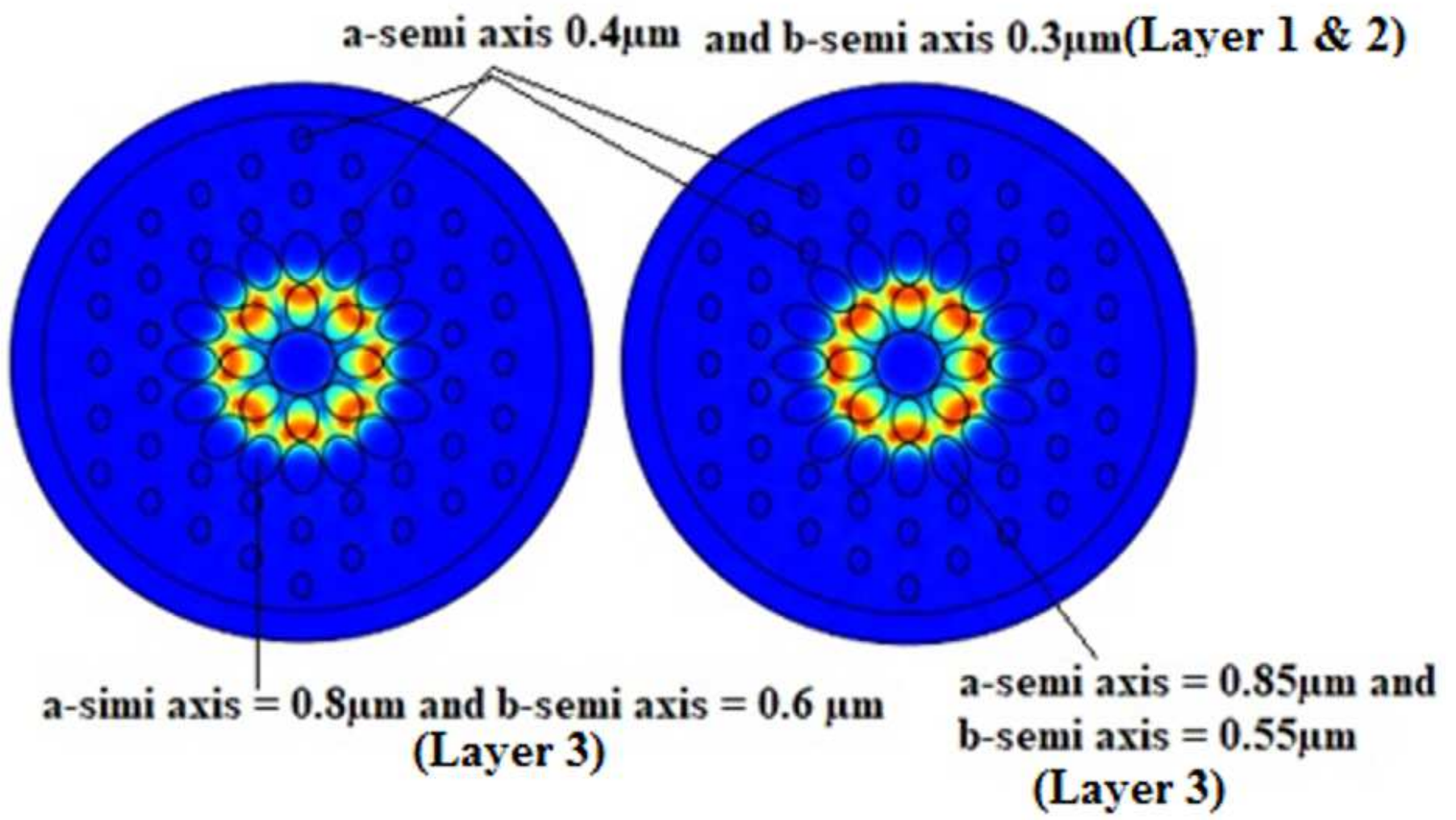

Figure 6

Light confinement for the two different 3rd layer (inner) cladding 


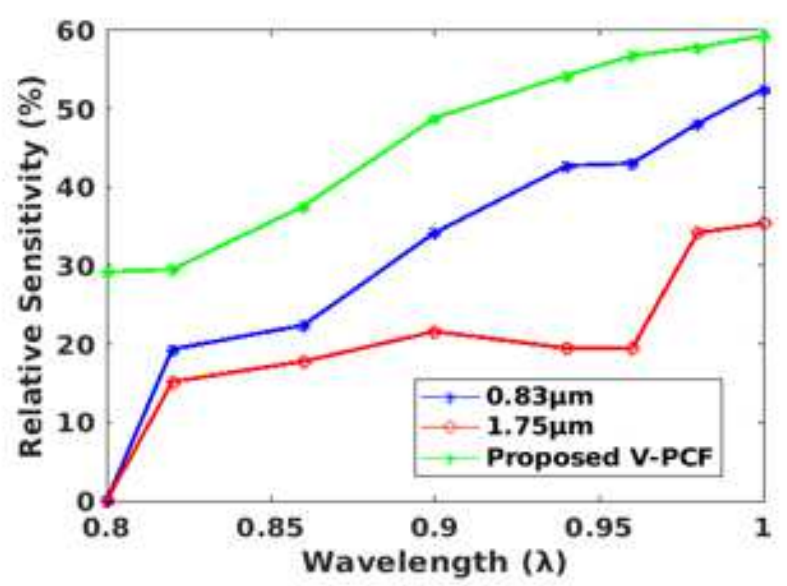

(a) Sensitivity of inner cladding

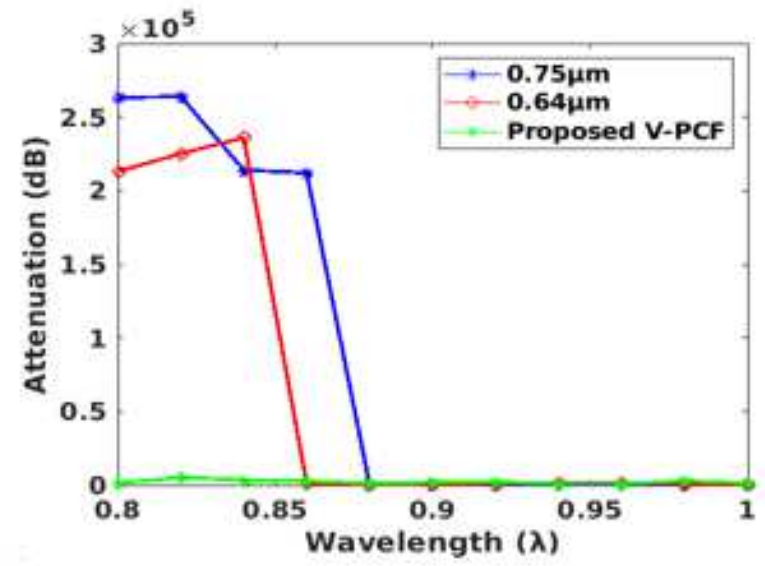

(c) Attenuation of inner cladding

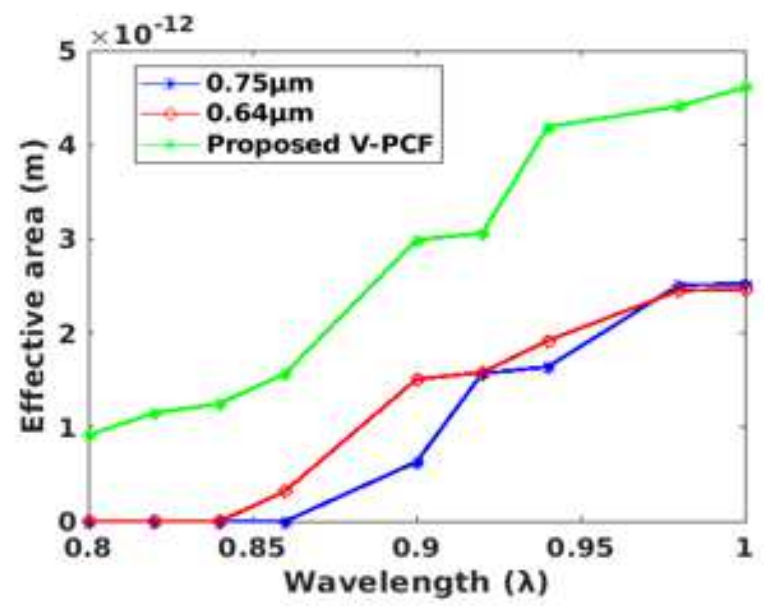

(b) Effective area of the inner cladding

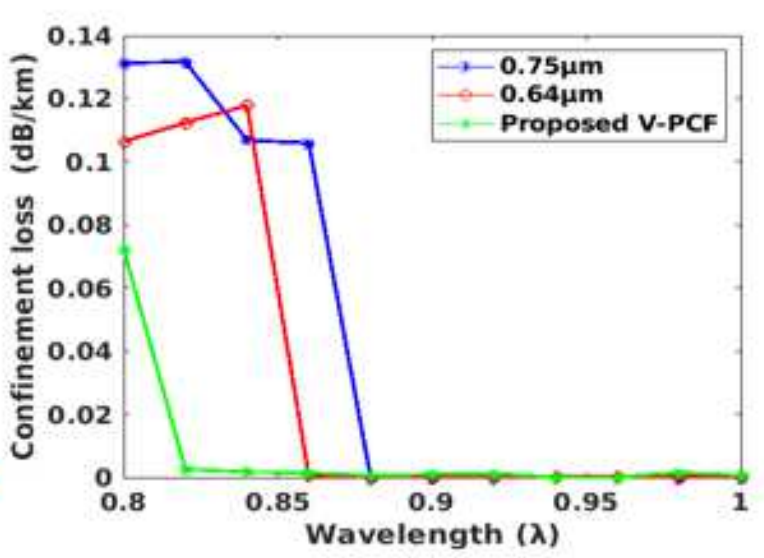

(d) Confinement loss of inner cladding

Figure 7

Analysis of various sensor parameters for the different inner cladding 


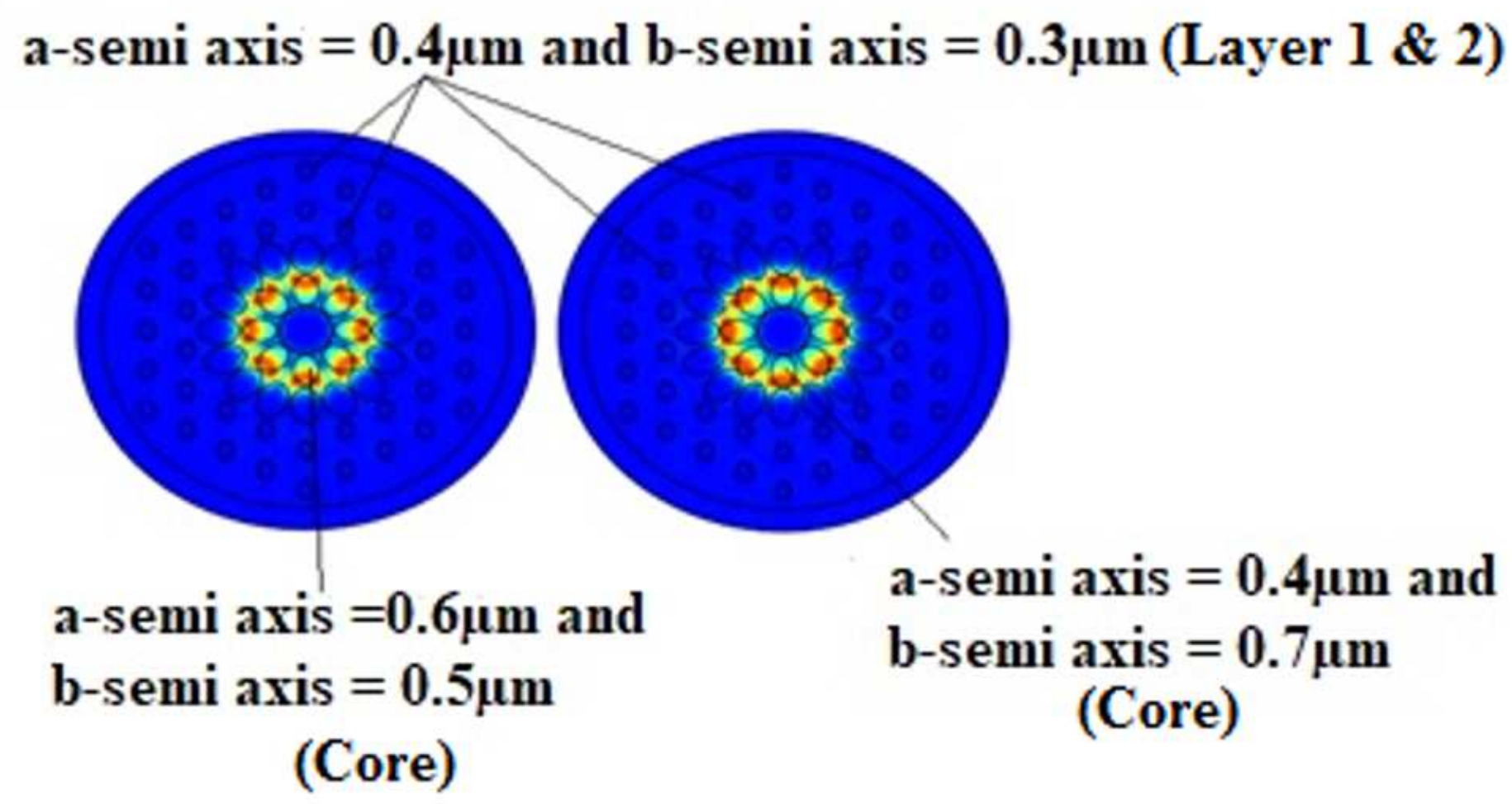

Figure 8

Light confinement for different core values in V-PCF 


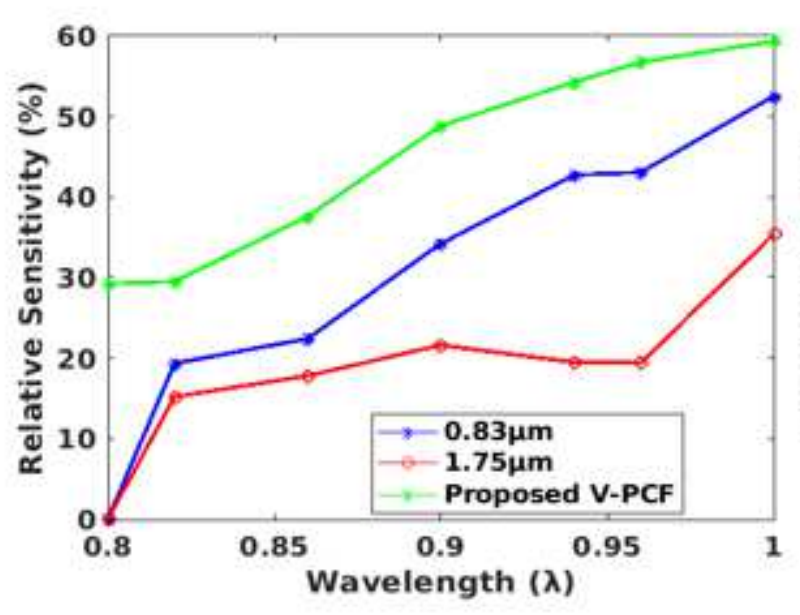

(a) Sensitivity of different core

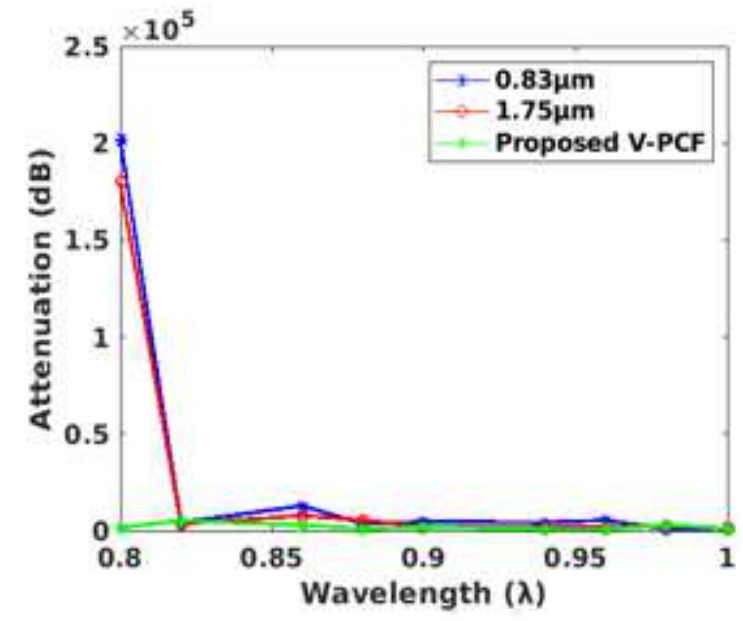

(c) Attenuation of different core

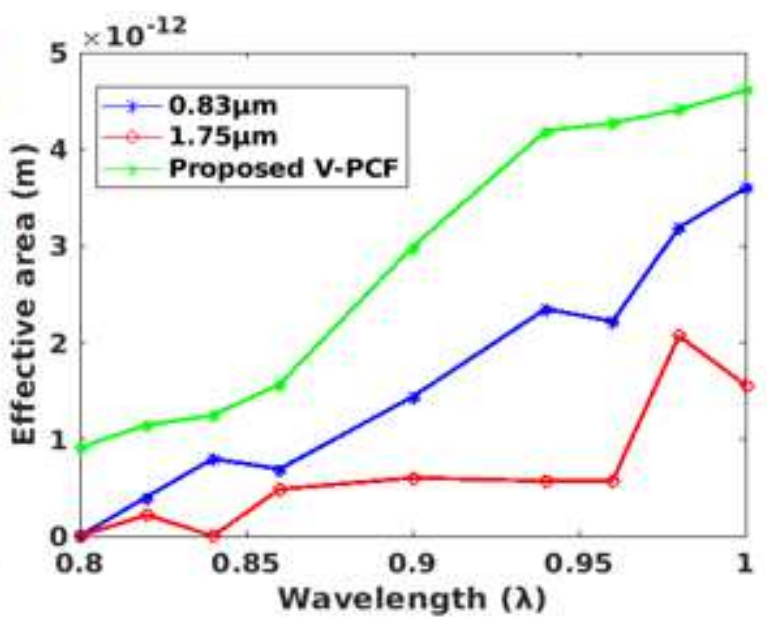

(b) Effective area of other core

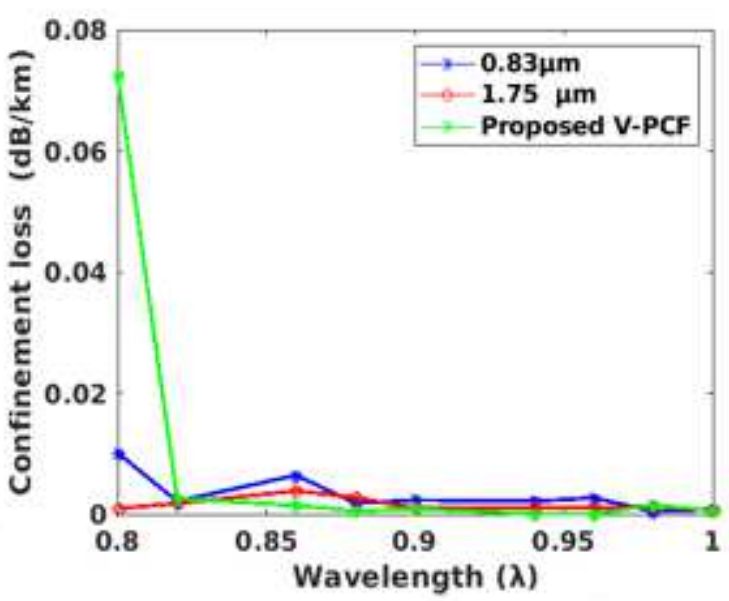

(d) Confinement loss of different core

Figure 9

Graph for the different core elliptical constant 


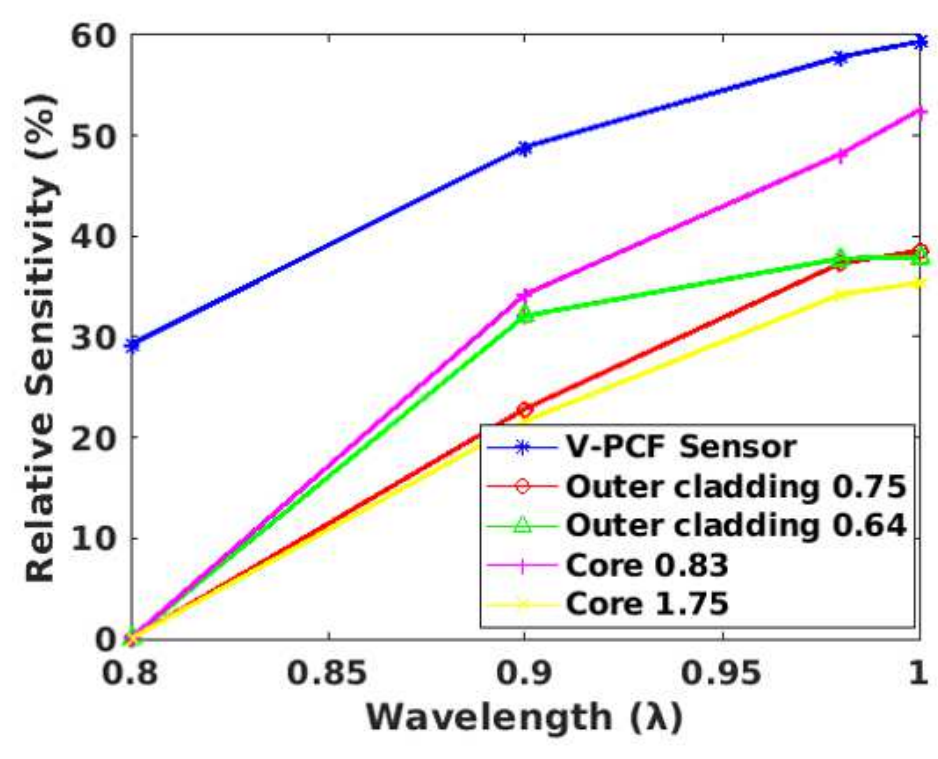

(a)

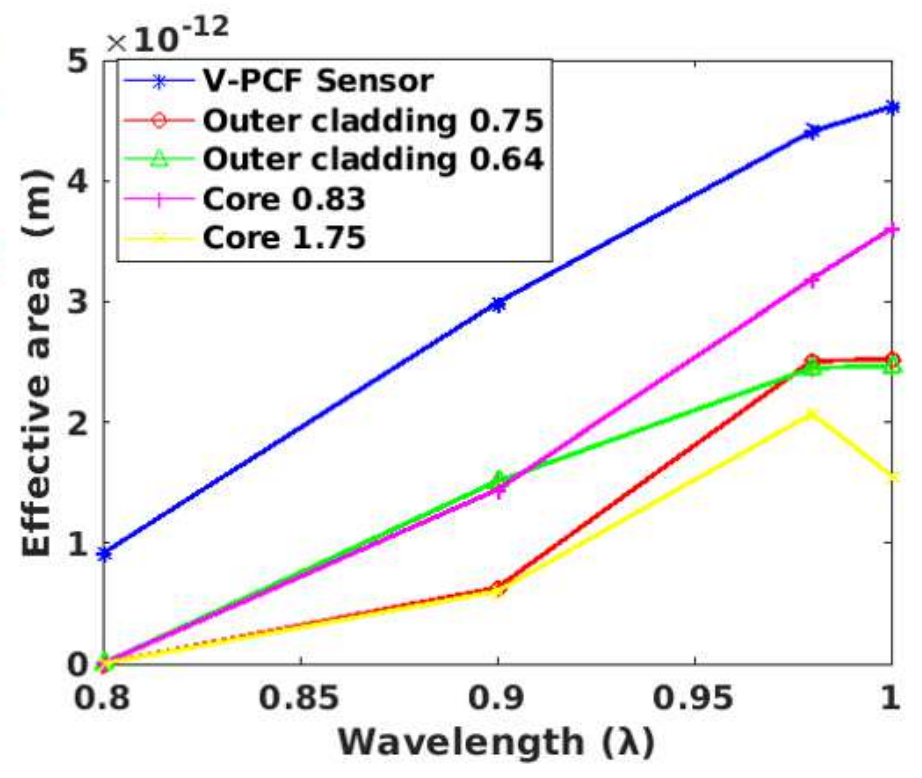

(b)

Figure 10

Wavelength vs. (a) Relative sensitivity of different cladding and core (b) Effective area of varying cladding and core 